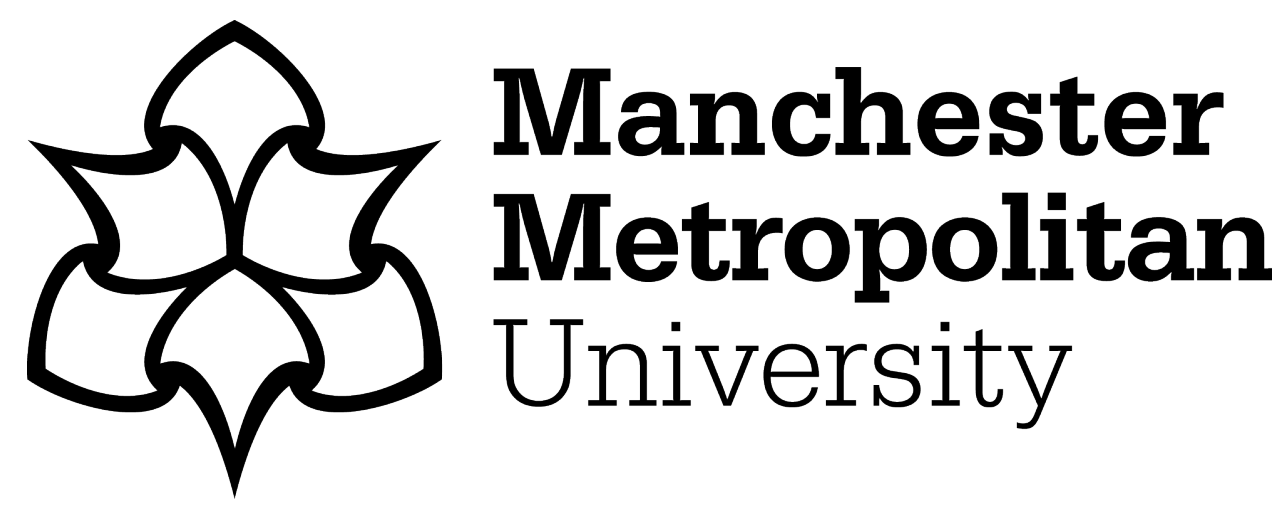

Qi, Shihan, Wu, Daxiong, Dong, Yan, Liao, Jiaqin, Foster, Christopher W ORCID logoORCID: https://orcid.org/0000-0002-5487-2803, O'Dwyer, Colm, Feng, Yuezhan, Liu, Chuntai and Ma, Jianmin (2019) Cobalt-based electrode materials for sodium-ion batteries. Chemical Engineering Journal, 370. pp. 185-207. ISSN 1385-8947

Downloaded from: https://e-space.mmu.ac.uk/622729/

Version: Accepted Version

Publisher: Elsevier BV

DOI: https://doi.org/10.1016/j.cej.2019.03.166

Usage rights: Creative Commons: Attribution-Noncommercial-No Derivative Works 4.0

Please cite the published version 


\title{
Cobalt-Based Electrode Materials for Sodium-Ion Batteries
}

\author{
Shihan Qi, ${ }^{a}$ Daxiong Wu,${ }^{a}$ Yan Dong,,${ }^{a}$ Jiaqin Liao,${ }^{a}$ Christopher W. Foster,${ }^{b, *}$ Colm \\ O'Dwyer, ${ }^{c, d, e *}$ Yuezhan Feng, ${ }^{f}$ Chuntai Liu ${ }^{f}$ and Jianmin $\mathrm{Ma}^{a, f, *}$
}

${ }^{a}$ School of Physics and Electronics, Hunan University, Changsha 410082, P.R. China

${ }^{b}$ Faculty of Science and Engineering, Manchester Metropolitan University, Manchester, Chester Street, M15 GD, UK

${ }^{c}$ School of Chemistry, University College Cork, Cork, T12 YN60, Ireland

${ }^{d}$ Tyndall National Institute, Lee Maltings, Cork, T12 R5CP, Ireland

${ }^{e}$ Environmental Research Institute, University College Cork, Lee Road, Cork T23 XE10, Ireland

${ }^{f}$ Key Laboratory of Materials Processing and Mold (Zhengzhou University), Ministry of Education, Zhengzhou University, Zhengzhou, 450002, China

\author{
Corresponding authors: Christopher W. Foster, Colm O'Dwyer or Jianmin Ma \\ Email addresses: \\ cwfoster90@gmail.com (Dr. Foster) \\ c.odwyer@ucc.ie (Prof. O’Dwyer) \\ nanoelechem@hnu.edu.cn (Prof. Ma)
}




\begin{abstract}
The demand for grid-scale energy storage systems has rapidly grown over recent years, to meet the requirements of structural innovation within the energy industry. Due to their inexpensive manufacturing and operating costs, and the similar electrochemical mechanism with the well-established lithium-ion batteries (LIBs), sodium ion batteries (SIBs) have been considered as an attractive candidate for grid-scale energy storage systems. A variety of cobalt-based cathode and anode materials, including cobalt oxides, cobalt chalcogenide and layered sodium cobaltate, have been synthesized and evaluated for sodium storage within the academic literature. In this article, we present a comprehensive review of the recent progress with cobalt-based electrodes (both as an anode and cathode material) used in SIBs. In detail, the electrochemical mechanisms, advantages and disadvantages, the relationship between crystalline structure and electrochemical performance and strategies to enhance the overall electrochemical performance of cobalt-based cathode and anode materials are discussed. Up to now, some cathode materials have already reached a high energy density, which is comparable to commercial LIBs. Furthermore, some cobalt-based materials can maintain a high Coulombic efficiency of over $99 \%$ with high reversible capacity during long cycling life. These encouraging results, allow such cobalt-based electrode materials to be a potential solution for grid-scale SIB systems.
\end{abstract}

Keywords: Sodium-ion batteries; Anode; Cathode; Cobalt oxides; Cobalt chalcognides 


\section{Introduction}

With the current alarming global pollution problem, the need to develop green renewable energies, and to reduce pollutant emission, is becoming more demanding and is one of the most pressing issues of this generation. As alternatives to traditional fossil energies, solar power, wind power, tidal power and other green energy technologies have rapidly developed over the last decade. As a result, this trend has led to a demand for new energy storage technologies, especially within stationary applications.[1, 2] Among the current energy storage technologies, the lithium-ion battery (LIB) has achieved great success, in particular within portable electronic equipment, and is predicted to dominate the electric vehicle market.[3-5] However, the limited reserves and ever-increasing cost of lithium and other critical raw materials casts doubt over whether this technology is also suitable for large-scale stationary applications. With abundant resource of sodium in both the earth's crust and oceans, the cost of sodium-containing materials is significantly lower than its lithium competitor.[6] For example, one of the most common sodium resource, Trona $\left(\mathrm{Na}_{2} \mathrm{CO}_{3}\right)$, is $\sim 20-30$ times cheaper than $\mathrm{Li}_{2} \mathrm{CO}_{3}$.[7] However, it should be noted that the weight of $\mathrm{Na}$ is three times higher than Li. Besides, the standard electrochemical potential of $\mathrm{Na}$ is lower than $\mathrm{Li}(2.71 \mathrm{~V}$ for $\mathrm{Na}$ and $3.04 \mathrm{~V}$ for $\mathrm{Li}$, vs. SHE).[8] These intrinsic properties result in a lower energy density for the sodium-ion battery (SIBs) over that of the LIB under similar conditions. Thus, SIBs have been regarded as a promising candidate for stationary energy storage devices, which is evident in the research of this technology over the last decade. . $[9,10]$

Unfortunately, however, the $\mathrm{Na}^{+}$ion does have a larger radius $(1.06 \AA)$ than that of the $\mathrm{Li}^{+}$ ions $(0.76 \AA)$, which in general will cause some problems for SIB materials. [8] The larger radius creates unstable cathodes and anodes during charge/discharge process, leading to a hindered cycling performance.[9, 10] Additionally, the $\mathrm{Na}^{+}$ion possesses a larger energy barrier for insertion into many electrode materials, which could conceivably pose a problem of limited capacity and poor rate capability. For example, graphite with a layer spacing of $3.35 \AA$, only shows a low irreversible capacity for SIBs.[11,12] Until now, these inferior cycling performances and rate capabilities still hinder the practical application of SIBs. To develop suitable electrode materials with an enhanced electrochemical performance is one of the key issues for the further advancement of SIBs.[13-15] An amount of materials have been studied as electrode materials for SIBs with a few offering acceptable electrochemical performance. For cathode materials, most 
research focus upon layered metallic oxides $\left(\mathrm{Na}_{\mathrm{x}} \mathrm{MO}_{2}, \mathrm{M}=\mathrm{Mn},[7] \mathrm{Co},[16,17] \mathrm{Ni},[18] \mathrm{Fe},[19]\right.$ $\mathrm{Cr}$,[20] etc), phosphates $\left(\mathrm{NaFePO}_{4},[21] \mathrm{Na}_{3} \mathrm{~V}_{2}\left(\mathrm{PO}_{4}\right)_{3},[22] \mathrm{NaVPO}_{4} \mathrm{~F},[23] \mathrm{Na}_{3} \mathrm{~V}_{2}\left(\mathrm{PO}_{4}\right)_{2} \mathrm{~F}_{3},[24]\right.$ $\mathrm{Na}_{1.5} \mathrm{VOPO}_{4} \mathrm{~F}_{0.5},[25] \mathrm{Na}_{2} \mathrm{FePO}_{4} \mathrm{~F},[26]$ etc), transition metal fluorides $\left(\mathrm{NaMF}_{3}, \mathrm{M}=\mathrm{Fe},[27] \mathrm{Mn}, \mathrm{V}\right.$ and $\mathrm{Ni}[28]$ ), and organic cathodes[29]. For anode materials, hard carbon,[14] metal alloys,[30] metal oxides[31] and chalcogenides[32,33] are promising candidates.

Cobalt, the $27^{\text {th }}$ element assigned to group VIII B, is a popular metal within material science. Cobalt-based materials have attracted much attention within many fields, including catalysis,[34] thermopower,[35] ferromagnetic properties,[36] energy storage[37-41] to name a few. Especially, for LIBs, $\mathrm{LiCoO}_{2}$ is one of the most successful commercialized cathode materials[42]. Similarly, cobalt-based materials can also play an important role in cathode and anode materials for SIBs.[43-48] The SIB cathode material, $\mathrm{Na}_{\mathrm{x}} \mathrm{CoO}_{2}$ is being investigated primarily because of the commercial success of $\mathrm{LiCoO}_{2}$ in the LIB. $[49,50]$ With respect to anode materials, cobalt oxides[51-53] and cobalt chalcogenides[54-57] demonstrate a high theoretical capacity for sodium storage. Full cell pairings of stable materials remain to be found and commercialized for SIBs.

We report a detailed review of the most recent advancements in cobalt-based materials for SIBs, with a focus on both cathode and anode electrode materials. This review covers the electrochemical mechanisms, a comparison of advantages and disadvantages, the relationship between crystalline structure and electrochemical performance, and strategies to enhance the overall electrochemical performance of cobalt-based cathode and anode materials. Finally, an overall outlook containing key challenges and perspectives on the future development of SIBs is provided.

\section{Cobalt Oxide Anodes}

\section{$2.1 \mathrm{Co}_{3} \mathrm{O}_{4}$}

Over the last decade, transition metal oxides (TMOs) have been core materials central to developments in semiconductor technologies, catalysis, sensing and energy storage to name a few. In particular, many TMOs, including $\mathrm{Fe}_{2} \mathrm{O}_{3},[58] \mathrm{Co}_{3} \mathrm{O}_{4},[59] \mathrm{MoO}_{3},[60] \mathrm{TiO}_{2},[61]$ etc, are regarded as promising candidates for the replacement of graphite anodes in batteries, due to their high alkaline ion storage capacity, for example $\mathrm{Co}_{3} \mathrm{O}_{4}$ possesses a high theory capacity of $890 \mathrm{mAh}$ $\mathrm{g}^{-1}$.[62] However, $\mathrm{Co}_{3} \mathrm{O}_{4}$ does possess an array of limitations, which is currently hindering its 
application as an anode material, such as limited electrical conductivity, poor ion diffusion kinetics, large volume expansion during $\mathrm{Na}^{+}$ion insertion and so on.[63, 64] Nanocrystallization and protective coating layer are generally considered as an effective methodology to enhance the electrochemical performance of $\mathrm{Co}_{3} \mathrm{O}_{4}$. Based on such viewpoint, a large number of nano-sized $\mathrm{Co}_{3} \mathrm{O}_{4}$ and $\mathrm{Co}_{3} \mathrm{O}_{4} / \mathrm{C}$ composites with various morphologies such as nanospheres,[65, 66] nanotubes,[67] hollow octahedra,[68] etc. have been reported within the literature.
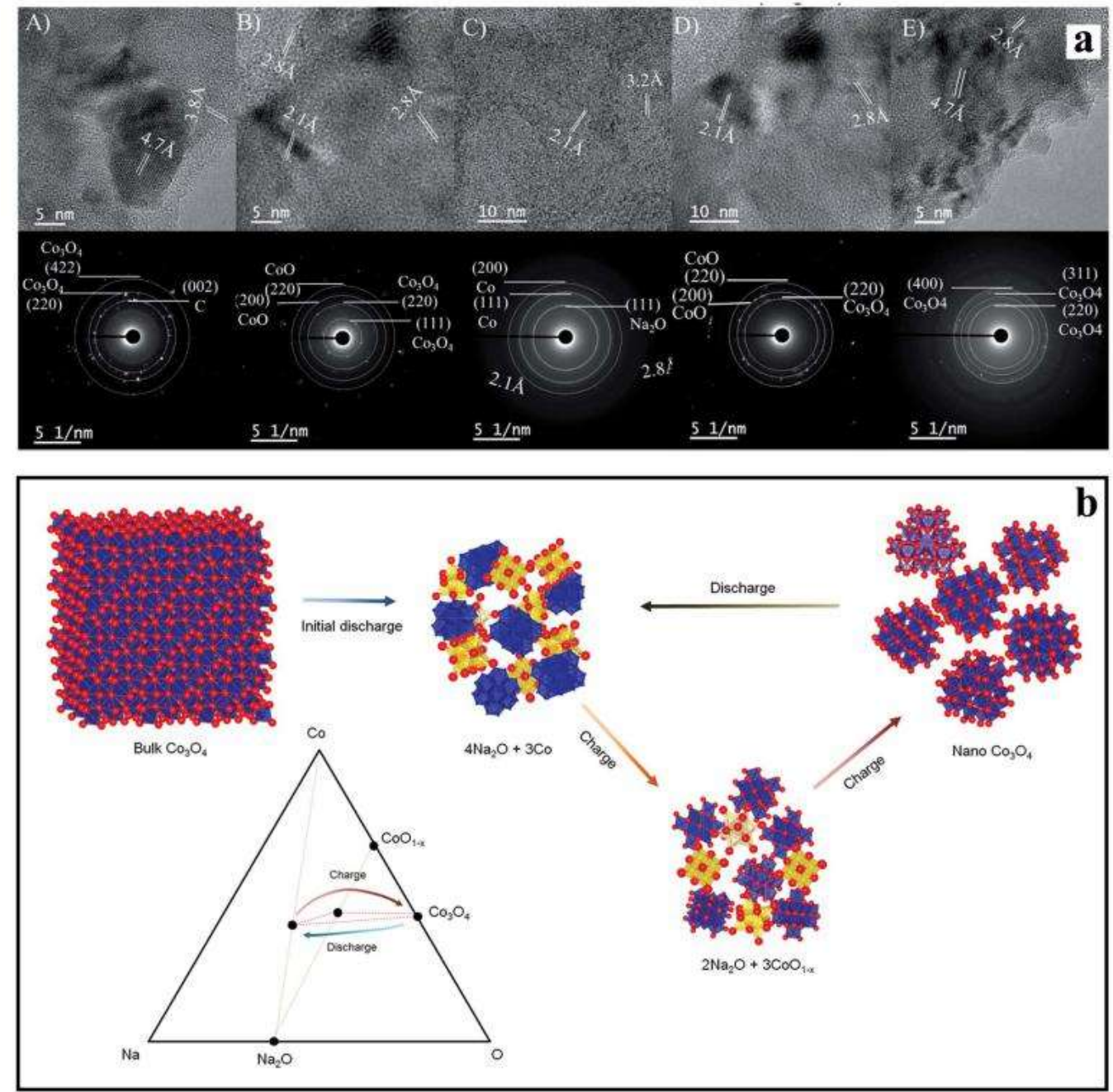

Fig. 1 Structural evolution of the $\mathrm{Co}_{3} \mathrm{O}_{4} @ \mathrm{NC}$ electrode during the electrochemical reaction. (a) TEM images (top) and selected area electron diffraction (SAED) patterns (bottom) at the corresponding points: A) pristine state, B) the discharged state at $0.6 \mathrm{~V}, \mathrm{C}$ ) fully discharged state at $0.01 \mathrm{~V}, \mathrm{D}$ ) the charged state at $1.4 \mathrm{~V}$ and E) the fully charged state at 3.0 V.[69] (b) Schematics of conversion and reconversion reaction mechanism for $\mathrm{Co}_{3} \mathrm{O}_{4}$ in Na rechargeable batteries.[70] 
As an anode material for sodium ion battery, $\mathrm{Co}_{3} \mathrm{O}_{4}$ goes through a conversion reaction during charge/discharge process.[69, 70] As can be seen in Fig 1a, the structural evolution of this material has been investigated systematically by ex-situ TEM and selected area electron diffraction (SAED) at different charge/discharge states. In detail, upon the $\mathrm{Na}^{+}$ion insertion, the $\mathrm{Co}_{3} \mathrm{O}_{4}$ phase gradually turns into a new phase of $\mathrm{CoO}$ over the voltage range of 3.0-0.6 V. In the fully discharged state at $0.01 \mathrm{~V}$, only $\mathrm{Co}$ and $\mathrm{Na}_{2} \mathrm{O}$ can be detected. Upon the subsequent charge process, the phases of $\mathrm{CoO}$ and $\mathrm{Co}_{3} \mathrm{O}_{4}$ emerge at $1.4 \mathrm{~V}$ and only the $\mathrm{Co}_{3} \mathrm{O}_{4}$ phase exists after fully charging at 3.0 V. Based upon these results, the conversion reaction during discharge process of $\mathrm{Co}_{3} \mathrm{O}_{4}$ with $\mathrm{Na}^{+}$ion can be summarized as :

$$
\begin{aligned}
& \mathrm{Co}_{3} \mathrm{O}_{4}+2 \mathrm{Na}^{+}+2 \mathrm{e}^{-} \rightarrow 3 \mathrm{CoO}+\mathrm{Na}_{2} \mathrm{O} \\
& 3 \mathrm{CoO}+6 \mathrm{Na}^{+}+6 \mathrm{e}^{-} \rightarrow 3 \mathrm{Co}+3 \mathrm{Na}_{2} \mathrm{O}
\end{aligned}
$$

It is well reported that bulk $\mathrm{Co}_{3} \mathrm{O}_{4}$ material, upon the charge/discharge, undergoes a morphological deterioration as the particle size reduces on the conversion reaction, (as demonstrated in Fig 1b)[70]. This effect lowers the electronic conductivity of the electrode, and can even result in the loss of active material. Such increases in surface area (due to the decreasing particle size) prevent the formation of a stable SEI membrane, often requiring SEI reformation to some degree in every cycle. To understand the morphological-performances correlations of $\mathrm{Co}_{3} \mathrm{O}_{4}$ materials, micro-sized $\mathrm{Co}_{3} \mathrm{O}_{4}$ slabs, nano-sized $\mathrm{Co}_{3} \mathrm{O}_{4}$ needles and nano-sized $\mathrm{Co}_{3} \mathrm{O}_{4}$ flakes were synthesized by Ruffo's group.[71] It is obvious from their data that the $\mathrm{Co}_{3} \mathrm{O}_{4}$ needles have the highest capacity and best cycling performance among them. It is believed that smaller size and larger surface area provides a shorter ion diffusion pathway and an increased availability of $\mathrm{Na}^{+}$ adsorption active sites, which leads to a higher capacity. In this case, the increase in grain boundary resistance with size reduction was not reported as a limiting factor in performance. Presumably, the nanoparticles are capable of withstanding the electrode stress caused by the material expansion.[72]

Another example within the literature to improve the stability of these metal oxides is their growth on conductive carbon substrates.[73-75] Recently, a form of $\mathrm{Co}_{3} \mathrm{O}_{4}$ mesoporous nanosheets/3D graphene composite $\left(\mathrm{Co}_{3} \mathrm{O}_{4} \mathrm{MNSs} / 3 \mathrm{DGN}\right)$, with an average pore size of about 40 $\mathrm{nm}$, was reported.[76] As displayed in Fig 2a-b, the introduction of graphene improves the overall conductivity of the composite and buffers the volume change of the cobalt oxide with the porous 
nanosheet structure benefiting the diffusion of $\mathrm{Na}^{+}$ions. As a result, this composite demonstrates an improved cycling performance and rate capability compared to $\mathrm{Co}_{3} \mathrm{O}_{4}$ nanosheets and $\mathrm{Co}_{3} \mathrm{O}_{4}$ nanoparticles. Using a Co-based MOF as a precursor to synthesize $\mathrm{Co}_{3} \mathrm{O}_{4} /$ carbon composites is another effective method. For example, several $\mathrm{Co}_{3} \mathrm{O}_{4}$ with a $\mathrm{N}$-doped carbon coating composites have been reported within the literature.[77]
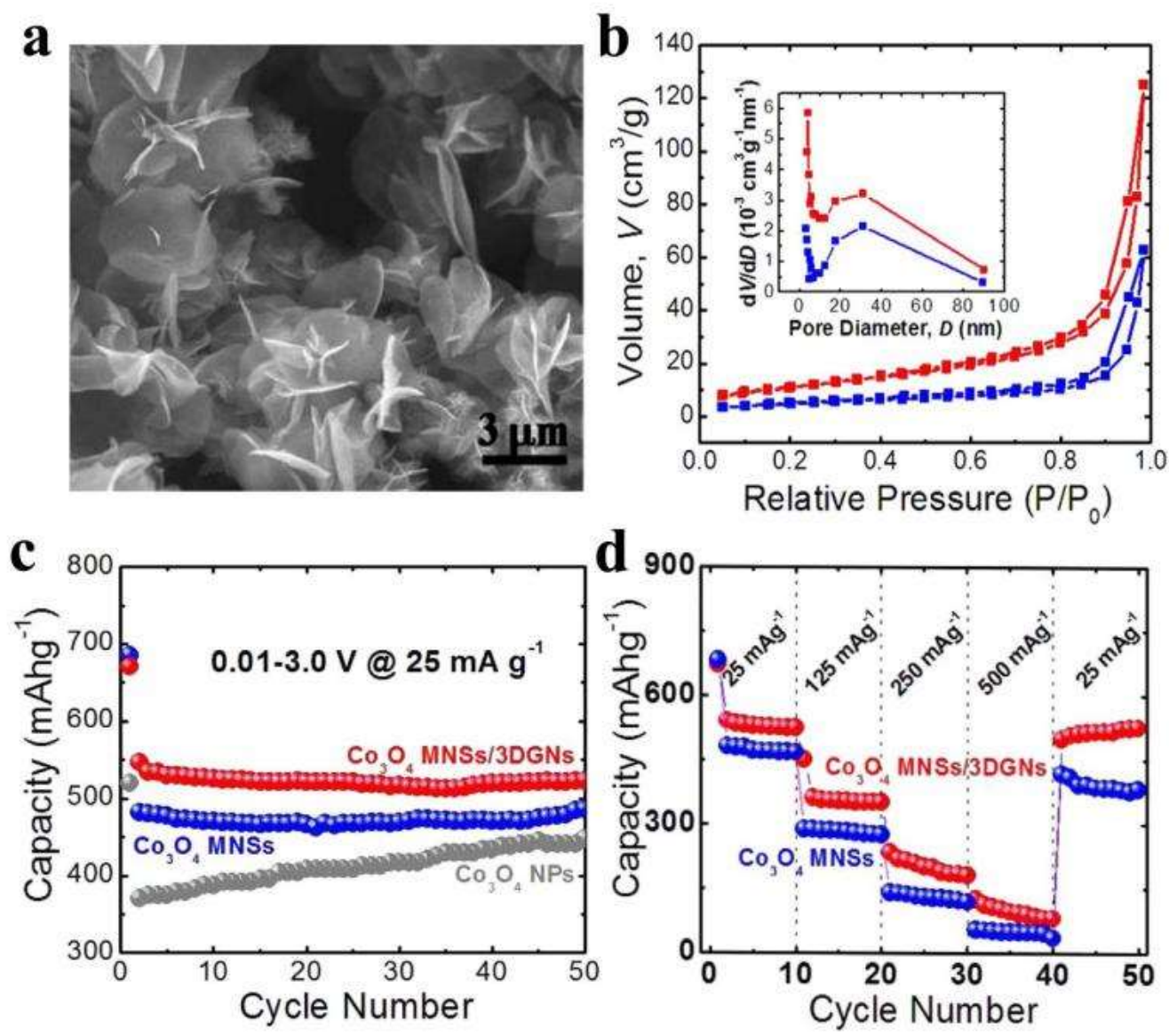

Fig. 2 Structural characterizations and electrochemical performances of $\mathrm{Co}_{3} \mathrm{O}_{4} \mathrm{MNSs} / 3 \mathrm{DGN}$. (a) FESEM image and (b) Nitrogen adsorption/desorption isotherms for $\mathrm{Co}_{3} \mathrm{O}_{4} \mathrm{MNSs} / 3 \mathrm{DGNs}$ nanohybrids (red lines) and $\mathrm{Co}_{3} \mathrm{O}_{4} \mathrm{MNSs}$ (blue lines). Inset: corresponding pore size distribution curves. (c) The cycling performance of $\mathrm{Co}_{3} \mathrm{O}_{4}-\mathrm{MNSs} / 3 \mathrm{DGNs}$ nanohybrids and $\mathrm{Co}_{3} \mathrm{O}_{4}$ MNSs. (d) Rate capability of the $\mathrm{Co}_{3} \mathrm{O}_{4}-\mathrm{MNSs} / 3$ DGNs nanohybrids and $\mathrm{Co}_{3} \mathrm{O}_{4}$ MNSs electrodes.[76]

Recently, some papers have proven that $\mathrm{Co}_{3} \mathrm{O}_{4} /$ metal oxide heterostructures also show good electrochemical performance in sodium ion batteries.[78, 79] is the rationale considered that an oxide heterostructure could potentially improve interfacial and surface charge transfer during 
charging and discharging. Thus, the composite with a heterostructure should possess a high electrical conductivity. For example, a novel graphene/ $\mathrm{SnO}_{2} / \mathrm{Co}_{3} \mathrm{O}_{4}(\mathrm{GSC})$ heterojunction material has been reported.[80] In detail, the $\mathrm{Co}_{3} \mathrm{O}_{4}$ is a p-type semiconductor with a band gap of $2.2 \mathrm{eV}$ and $\mathrm{SnO}_{2}$ is an n-type semiconductor with a wider band gap of $3.8 \mathrm{eV}$. In the discharge process, the direction of the internal electric field should point from the $\mathrm{SnO}_{2}$ side to $\mathrm{Co}_{3} \mathrm{O}_{4}$ side as an effective p-n junction. Based on the inbuilt depletion region, the accumulation of charge at the interfaces can be reduced. This is beneficial to the $\mathrm{Na}^{+}$ion's diffusion and insertion into this material, as shown in Fig. 3a according to the authors. A smaller charge transfer impedance of the graphene $/ \mathrm{SnO}_{2} / \mathrm{Co}_{3} \mathrm{O}_{4}$ composite compared to the graphene/ $\mathrm{SnO}_{2}(\mathrm{GS})$ can be observed. As a result, graphene $/ \mathrm{SnO}_{2} / \mathrm{Co}_{3} \mathrm{O}_{4}$ demonstrates better cyclic performance than the composite without a heterostructure. The same trend can also be obtained with $\mathrm{ZnO} / \mathrm{Co}_{3} \mathrm{O}_{4}[81]$ and $\mathrm{Co}_{3} \mathrm{O}_{4} / \mathrm{MnO}_{2}[82]$ composites. In addition, doping with metallic ions ( $\operatorname{such}$ as $\mathrm{Zn}^{2+}$ and $\mathrm{Ni}^{2+}$ ) is another effective way to enhance the sodium storage properties.[83]

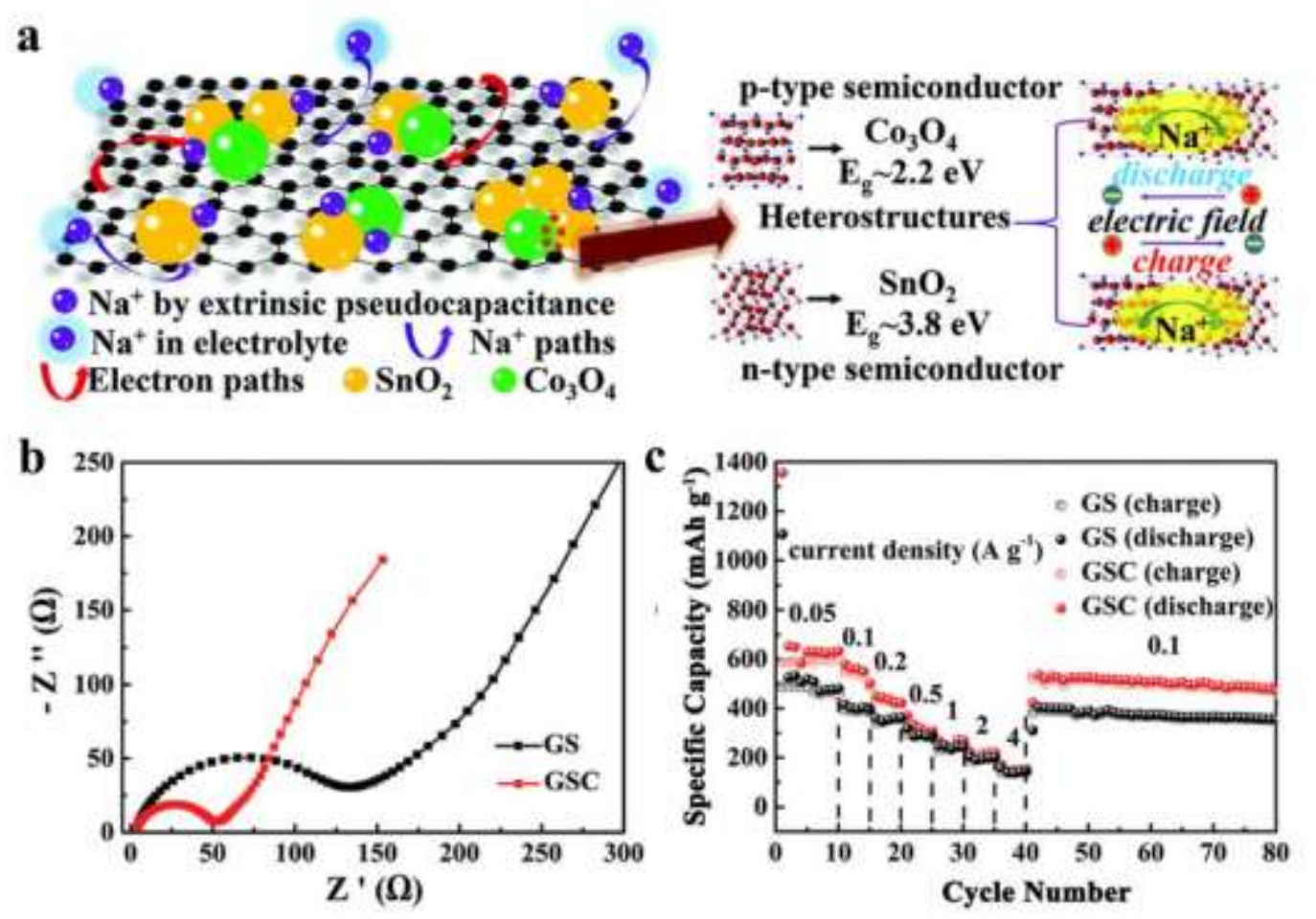

Fig. 3 (a) Summary of the enhanced high-rate capacity mechanism of the GSC anodes in the Na-ion battery system. (b) The Nyquist plots of GSC and GS. (c) Rate performance of GSC and GS at applied various current densities.[80] 


\section{$2.2 \mathrm{CoO}$}

Besides $\mathrm{Co}_{3} \mathrm{O}_{4}$, several recent reports have focused on $\mathrm{CoO}$ for application in a sodium ion battery. During the $\mathrm{Na}^{+}$insertion process, the electrochemical reaction of $\mathrm{CoO}$ can be concluded as the following[84]:

$$
\mathrm{CoO}+2 \mathrm{Na}^{+}+2 \mathrm{e}^{-} \rightarrow \mathrm{Co}+\mathrm{Na}_{2} \mathrm{O}
$$

Based on this above reaction, $\mathrm{CoO}$ exhibits a sodium storage capacity of $715 \mathrm{mAh} \mathrm{g}^{-1}$.[85] The short cycling life and terrible rate capability also challenge the development of the $\mathrm{CoO}$ electrode for the sodium ion battery. To address these limitations, a porous $\mathrm{Ni}$-doped $\mathrm{Co} / \mathrm{CoO} / \mathrm{carbon}$ composite was recently reported.[86] Due to a stated synergistic effect of the carbon coating, highly porous structure, and defect sites caused by Ni-doping, the structural stability, electric and ionic conductivity are improved simultaneously. This material demonstrates a capacity of 307 $\mathrm{mAh} \mathrm{g}^{-1}$ at $0.1 \mathrm{~A} \mathrm{~g}^{-1}$ and a relatively high discharge capacity of about $280 \mathrm{mAh} \mathrm{g}^{-1}$ is observed after 100 cycles at the same current density.

\section{Cobalt Sulfide Anodes}

\section{$3.1 \mathrm{Cog}_{8}$}

$\mathrm{Co}_{9} \mathrm{~S}_{8}$ has attracted great attention over a range of fields of research including catalysis, sensing and energy storage, due to its unique physical and electrochemical properties.[87] As can be seen in Fig 4, cubic $\mathrm{Co}_{9} \mathrm{~S}_{8}$ has a space group of $\mathrm{Fm}-3 \mathrm{~m}$, and a large unit cell parameter of $\mathrm{a}=$ $9.926 \AA$. As shown in Fig 4, its crystal structure comprises two different polyhedra, $\mathrm{CoS}_{6}$ octahedra and $\mathrm{CoS}_{4}$ tetrahedra, respectively.[88] In a perfect crystal structure, every $\mathrm{CoS}_{6}$ octahedron shares its corners with $24 \mathrm{CoS}_{4}$ octahedrons. There are three different Co-S bonds with varying bond lengths and energy. This form of structure can not only provide channels for ionic diffusion, but also offers multiple possible routes of bonding-breaking. 


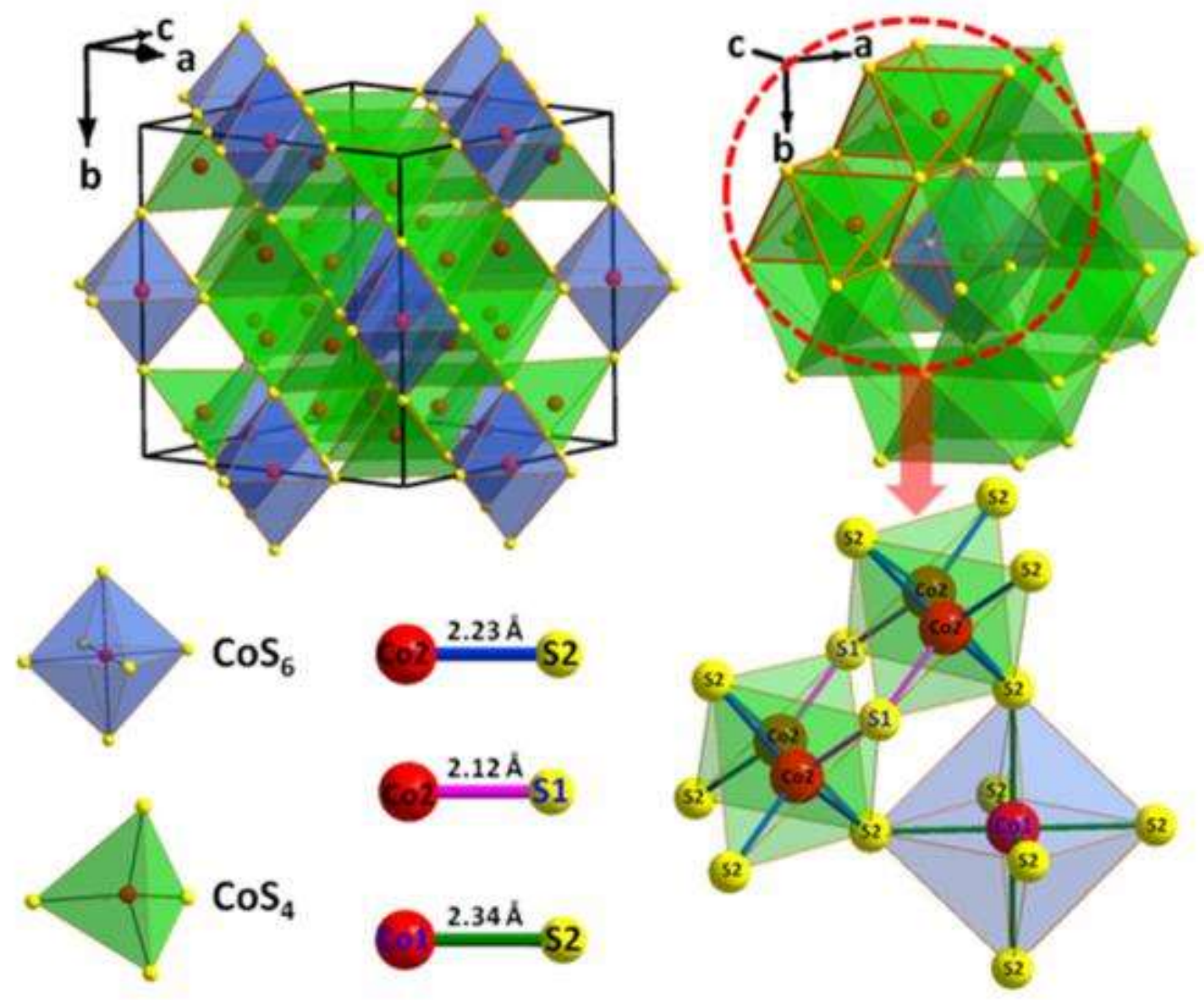

Fig. 4 Schematic structure of cube $\mathrm{Co}_{9} \mathrm{~S}_{8} .[88]$

Through different synthesis methods, such as solvothermal and solid state recrystallization, $\mathrm{Co}_{9} \mathrm{~S}_{8}$-based materials with various morphologies have been obtained.[89, 90] In the energy storage field, engineering these structure to have a large surface area and be capable of high capacity alkaline ion storage properties, nano-sized $\mathrm{Cog}_{9} \mathrm{~S}_{8}$ has been widely studied as an electrode material for supercapacitor and lithium ion battery applications. When applied to sodium ion battery systems, $\mathrm{Co}_{9} \mathrm{~S}_{8}$ suffers a conversion reaction according to $\mathrm{Co}_{9} \mathrm{~S}_{8}+16 \mathrm{Na}^{+} \rightarrow 9 \mathrm{Co}+8$ $\mathrm{Na}_{2} \mathrm{~S}$, which shows a relatively high theoretical capacity of $544 \mathrm{mAh} \mathrm{g}^{-1}$.[91] However, the low degree of reversibility and excessive volume changes caused by the above conversion reaction leads to very poor cycling performance and rate capability, in addition to the unstable solid electrolyte interphase, which also aggravates this problem.[92]

To enhance the electrochemical performance of $\mathrm{Co}_{9} \mathrm{~S}_{8}$ as an anode for sodium ion batteries, several strategies have been reported. For example, hierarchical nanostructuring can play a vital 
role for a conductive substrate, buffering the stress caused by the change in volume and offer open channels for $\mathrm{Na}^{+}$ion diffusion and for mass transport of other reactants in conversion mode processes. Novel $\mathrm{Co}_{9} \mathrm{~S}_{8}$ quantum dots embedded into hierarchical porous carbon frameworks (3DOM Co9 $\mathrm{S}_{8}-\mathrm{QDs} @ \mathrm{NC}$ ) was obtained by a template method, as shown in Fig 5a.[89] The $\mathrm{SiO}_{2}$ nanospheres were utilized as a sacrificial template and were etched to form macropores with an average size of $150 \mathrm{~nm}$ and the surface-immobilized $\mathrm{Cog}_{9} \mathrm{~S}_{8}$ quantum dots are $\sim 3 \mathrm{~nm}$ (Fig $5 \mathrm{~b}$ ) in size. This composite exhibits an improved cycling performance and rate capability compared to the $\mathrm{Co}_{9} \mathrm{~S}_{8} / \mathrm{C}\left(\mathrm{Co}_{9} \mathrm{~S}_{8}-\mathrm{QDs} @ \mathrm{NC}\right)$ without hierarchical structure by ensuring good interfacial contact and QD access to the electrolyte. In detail, as can be seen in Fig 5c, when the current density reaches to $10 \mathrm{~A} \mathrm{~g} \mathrm{~g}^{-1}$, this composite still shows a remarkable specific capacity of $253 \mathrm{mAh} \mathrm{g}^{-1}$. Moreover, a capacity of more than $340 \mathrm{mAh} \mathrm{g}^{-1}$ is achieved after 2000 cycles with the Coulombic efficiency of over $99 \%$, at a current density of $1 \mathrm{~A} \mathrm{~g}^{-1}$. Beyond all the above-mentioned reasons of hierarchical structure, the high ratio of diffusion-controlled capacity is another significant reason for the improved electrochemical performance.

Utilizing a Co-based MOF as the precursor is another effective way to synthesize a hierarchical $\mathrm{Co}_{9} \mathrm{~S}_{8}$-based material. Several studies have proved that ZIF-67 is the suitable precursor for this strategy. For instance, recently, a $\mathrm{Co}_{9} \mathrm{~S}_{8}$ quantum dot/hollow carbon matrix/graphene aerogel was synthesized with the ZIF-67 precursor.[92] This composite demonstrated a stable cycling life over 500 cycles at a current density of $300 \mathrm{~mA} \mathrm{~g}^{-1}$. Similarly, most capacity is contributed by the diffusion-controlled electrochemical behavior.

Combining with other metal sulfides to form heterostructures can also enhance the sodium storage capacity of $\mathrm{Co}_{9} \mathrm{~S}_{8} . \mathrm{MoS}_{2}$ is another alternative anode material for SIB. For good wettability with organic electrolyte, $\mathrm{MoS}_{2}$ can play a role as a useful coating layer for other materials.[93] A type of $\mathrm{Co}_{9} \mathrm{~S}_{8}$ core- $\mathrm{MoS}_{2}$ shell composite $\left(\mathrm{Co}_{9} \mathrm{~S}_{8} / \mathrm{MoS}_{2}-\mathrm{CN}\right)$ shows more stable cycling life and better rate capability than pure $\mathrm{Co}_{9} \mathrm{~S}_{8}$ or pure $\mathrm{MoS}_{2}$, as shown in Fig 5f-g.[94] It is believed that $\mathrm{MoS}_{2}$ shell can bring such advantages: smaller Ohmic resistance, lower activation energy for $\mathrm{Na}^{+}$ion diffusion and larger exposed surface to the electrolyte, which leads to an improved electrochemical performance. In addition, of the choice of electrolyte will have a significant impact on the sodium storage capacity of a $\mathrm{C}_{9} \mathrm{~S}_{8}$ electrode. It has been reported that an ether-based electrolyte, such as $1.0 \mathrm{M}$ sodium trifluomethanesulfonate $\left(\mathrm{NaCF}_{3} \mathrm{SO}_{3}\right)$ dissolved in 
tetraethylene glycol dimethyl ether (TEGDME), can bring a much more stable long-term cycling life and good rate capability.[90]
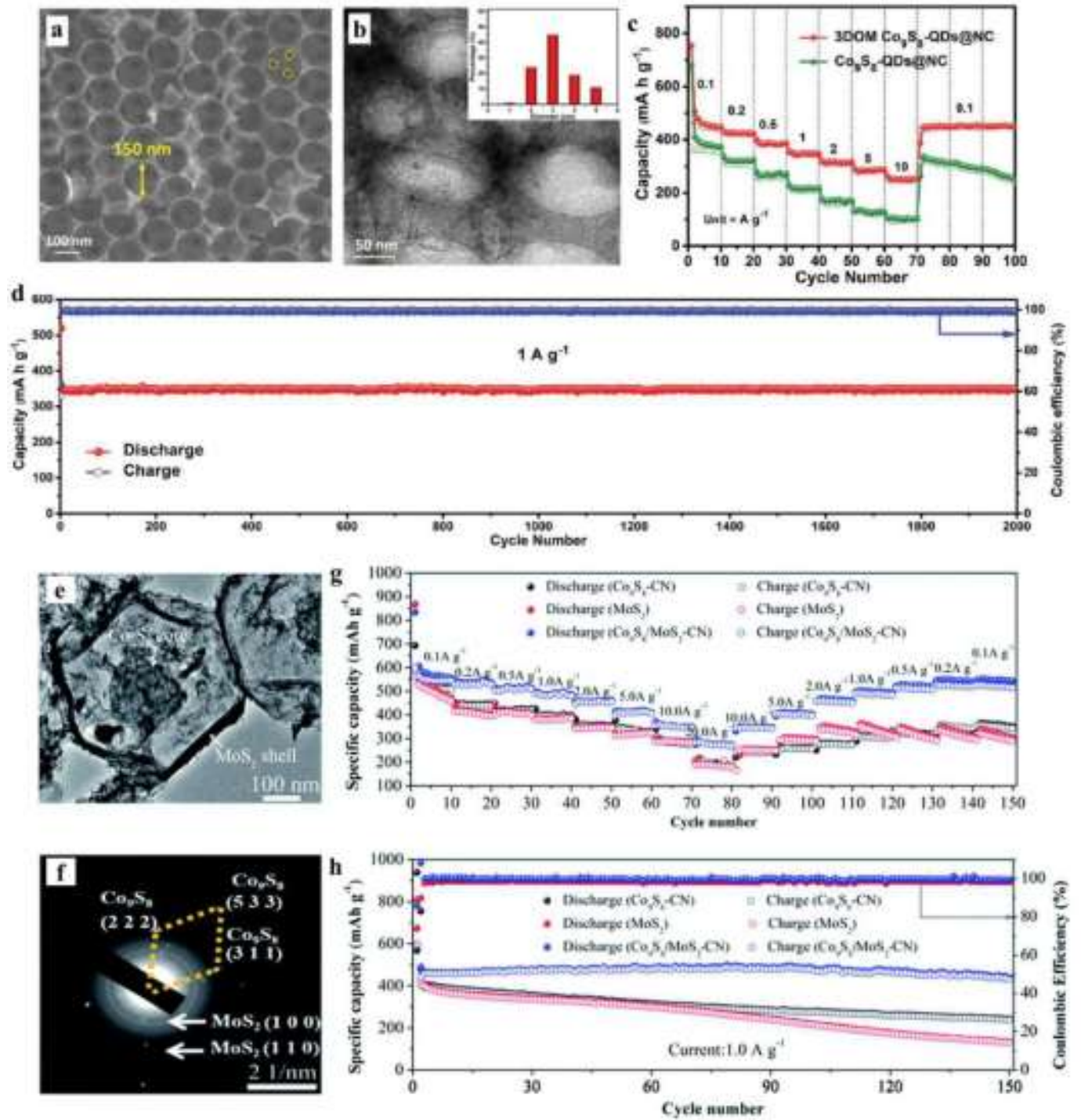

Fig. 5 (a) FESEM images and (b) TEM images with inset of the size distribution of the QDs for 3DOM Co9 $\mathrm{S}_{8}-\mathrm{QDs} @ N C$. (c) Rate capability of the 3DOM Cog9 $\mathrm{S}_{8}-\mathrm{QDs} @ N C$ and $\mathrm{Cog}_{9} \mathrm{~S}_{8}-\mathrm{QDs} @ N C$ electrode. (d) Cycling performance and Coulombic efficiency of 3DOM Cog958-QDs@NC for 2000 cycles at the current density of $1 \mathrm{~A} \mathrm{~g}^{-1}$.[89] $\quad$ (e) TEM images and (f) SAED patterns of the yolk-shelled polyhedral $\mathrm{Co}_{9} \mathrm{~S}_{8} / \mathrm{MoS}_{2}-\mathrm{CN}$ nanocomposite. (g) Rate capability at different current densities and (h) cycling performance at $1.0 \mathrm{~A} \mathrm{~g}^{-1}$ for the $\mathrm{Co}_{9} \mathrm{~S}_{8} / \mathrm{MoS}_{2}-\mathrm{CN}$ composite, $\mathrm{Co}_{9} \mathrm{~S}_{8}-\mathrm{CN}$ and $\mathrm{MoS}_{2}$ anodes.[94] 
$3.2 \mathrm{CoS}_{2}$

$\mathrm{CoS}_{2}$ has the same crystal structure as $\mathrm{FeS}_{2}$, which is called a pyrite phase. The schematic representation of the $\mathrm{CoS}_{2}$ crystal structure is displayed in Fig 6.[95] A Co atom occupies the central site of an octahedral arrangement with $\mathrm{S}$ atoms occupying the corner site the neighboring octahedrons share corners with each other. Besides, $\mathrm{CoS}_{2}$ is assigned to a cubic phase with the $P a-3$ space group.

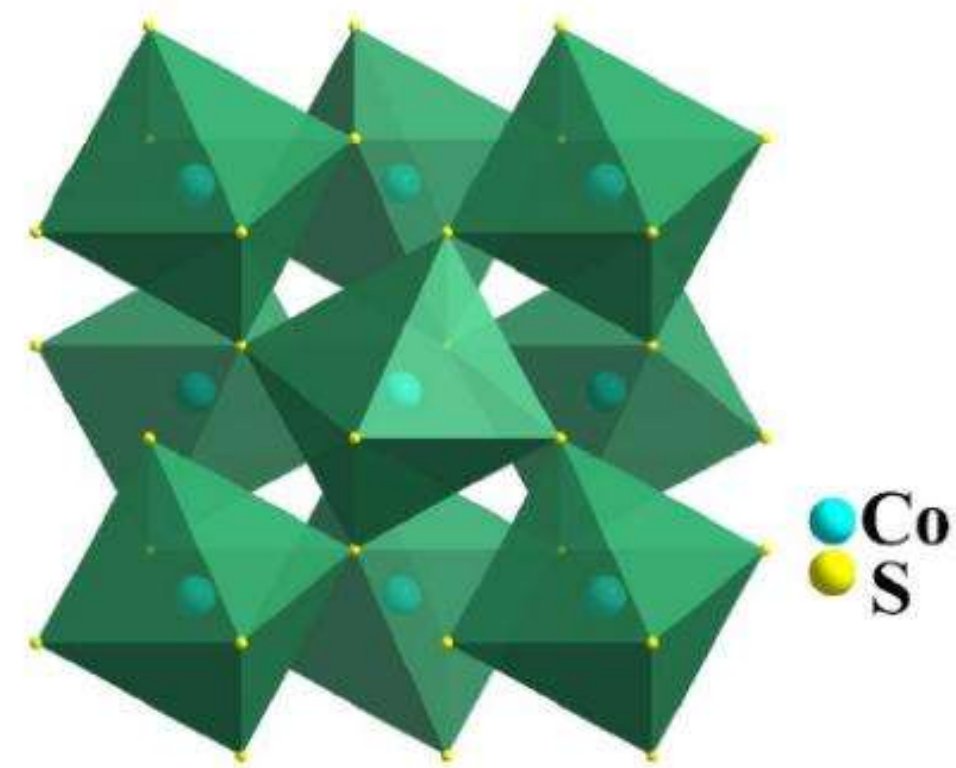

Fig. 6 Crystal structure of $\mathrm{CoS}_{2}$.[95]

As a promising anode material for SIBs, $\mathrm{CoS}_{2}$ offers a large theoretical capacity of $870 \mathrm{mAh}$ $\mathrm{g}^{-1}$ and high electronic conductivity. $[96,97]$ The band gap of $\mathrm{CoS}_{2}$ is $0 \mathrm{eV}$, which means this material possesses metallic-like conductivity. According to previous work,[98] as can be seen in Fig 7, each $\mathrm{CoS}_{2}$ can react with four $\mathrm{Na}^{+}$ions and this electrochemical reaction can be divided into 2 steps. Firstly, when the voltage is above $1 \mathrm{~V}\left(v s . \mathrm{Na}^{+} / \mathrm{Na}\right)$, no more than two $\mathrm{Na}^{+}$ions inserted into $\mathrm{CoS}_{2}$ and an intermediate product is formed. Then, with the electrochemical reaction proceeding, $\mathrm{Co}^{4+}$ is reduced to metallic $\mathrm{Co}$ and $\mathrm{Na}_{2} \mathrm{~S}$ emerged below $1 \mathrm{~V}\left(v s . \mathrm{Na}^{+} / \mathrm{Na}\right)$. The sluggish kinetics, low reversibility and huge volume change for conversion reaction that takes place in the low voltage range, causes inferior cycling performance. To solve this problem is one of the key issues for $\mathrm{CoS}_{2}$ as an anode material for sodium ion battery.[99] 


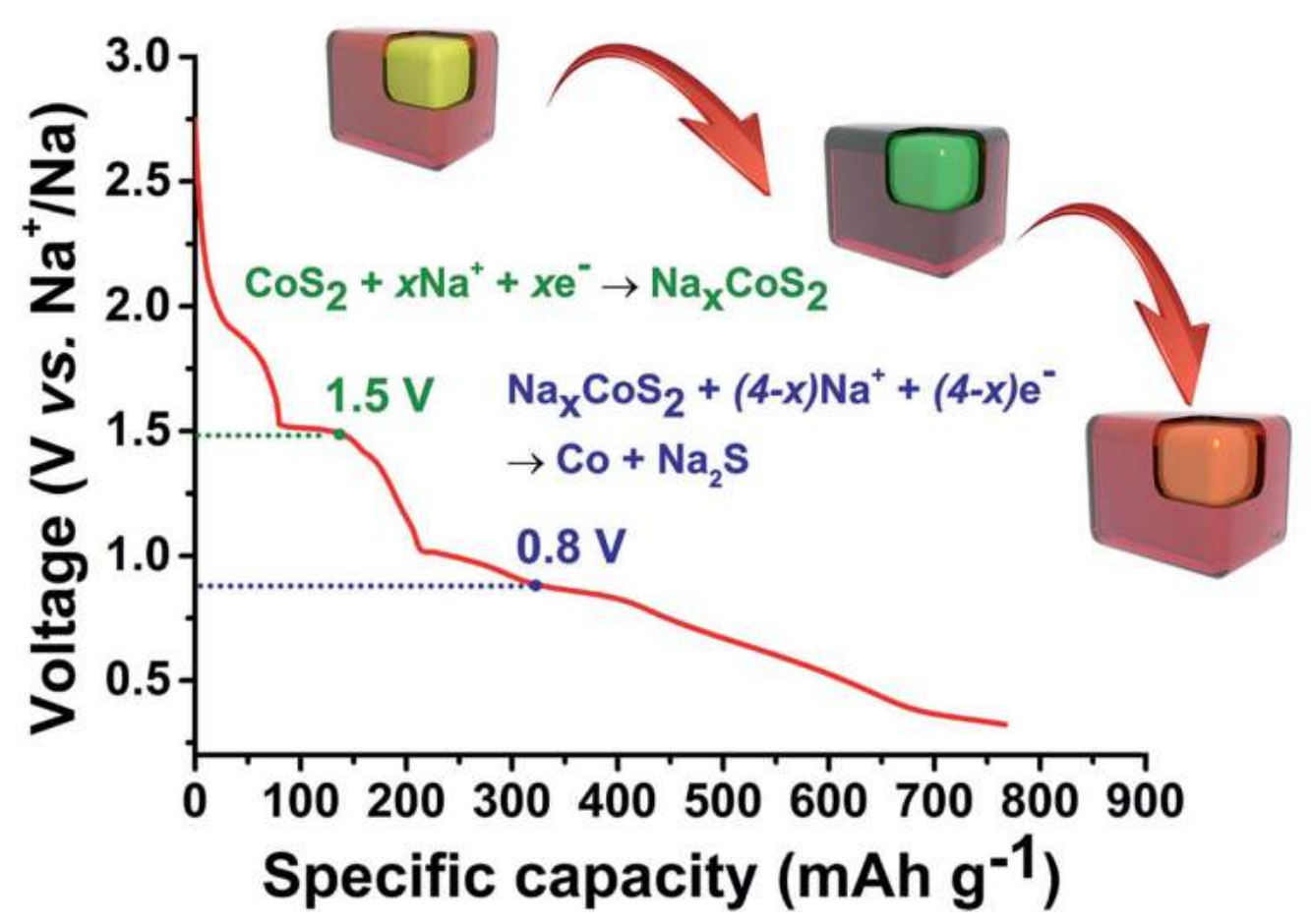

Fig. 7 Reaction mechanisms of $\mathrm{CoS}_{2}$ in the fully discharged process.[98]

Carbon matrices or coating layers can buffer the volume change of $\mathrm{CoS}_{2}$ during intercalation-deintercalation of $\mathrm{Na}^{+}$ions and associated reaction phases. Previous work has tried to introduce carbon-based materials to obtain a $\mathrm{CoS}_{2}$-based composite with good electrochemical performance.[100-102] A kind of flower-like $\mathrm{N}$-doped carbon/ $\mathrm{CoS}_{2}$ spheres $\left(\mathrm{N}-\mathrm{C} / \mathrm{CoS}_{2}\right)$ was synthesized by a solvothermal method followed by sulfurization.[103] As can be seen in Fig 8a, the $\mathrm{CoS}_{2}$ flowers consist of $2 \mathrm{D}$ wrinkled $\mathrm{CoS}_{2}$ nanosheets with an average thickness less than 5 $\mathrm{nm}$. This open nanostructure can shorten the $\mathrm{Na}^{+}$ion diffusion distance in the $\mathrm{CoS}_{2}$ crystal in principle. Combined with the carbon matrix, this composite shows a stable cycling life over 500 cycles without obvious capacity decay. In contrast, bare $\mathrm{CoS}_{2}$ loses most of its capacity after 200 cycles. In another work, combining the template, electrospinning and solvothermal methods, a double-morphology $\mathrm{CoS}_{2}-\mathrm{N}$ doped carbon fiber composite was synthesized.[104] As can be seen in Figure 8c, $\mathrm{CoS}_{2}$ nanosheets were in situ formed on the surface of the carbon fiber. Meanwhile, $\mathrm{CoS}_{2}$ nanoparticles also grew in the channels of these carbon fibers. This form of carbon fiber, with unique its structure, plays the dual role of matrix and coating for $\mathrm{CoS}_{2}$ nanosheets and nanoparticles, respectively. At $0.1 \mathrm{~A} \mathrm{~g} \mathrm{~g}^{-1}$, this composite exhibits a high initial discharge capacity of 849.6 $\mathrm{mAh} \mathrm{g}^{-1}$, and maintains capacities of more than $700 \mathrm{mAh} \mathrm{g}^{-1}$ over subsequent cycles. In 
addition, compared with the bare $\mathrm{CoS}_{2}$ electrode, double-morphology $\mathrm{CoS}_{2}-\mathrm{N}$ doped carbon fiber composite demonstrate a more stable long-term cycling over 900 cycles.

Similar to $\mathrm{Co}_{9} \mathrm{~S}_{8}$, heterostructures consisting of $\mathrm{CoS}_{2}$ and other metal sulfides have also been reported.[105] $\mathrm{SnS}_{2} @ \mathrm{CoS}_{2}-\mathrm{rGO}$ (reduced graphene oxide) composite shows quite a high discharge capacity and better cycling performance than $\mathrm{SnS}_{2}-\mathrm{rGO}$ and $\mathrm{CoS}_{2}-\mathrm{rGO}$ composites.[106] It is believed that a synergetic effect exists between $\mathrm{CoS}_{2}$ and $\mathrm{SnS}_{2}$, which can offer an optimal electrode/electrolyte interface. Using Prussian blue analogues, potassium hexacyanocobaltate as a precursor, a type of $\mathrm{NiS}_{2} @ \mathrm{CoS}_{2} @ \mathrm{C} @ \mathrm{C}$ nanocube was obtained.[107] This material also shows a stable cycling life, with more than $600 \mathrm{mAh} \mathrm{g}^{-1}$ capacity obtained after 250 cycles, at a current density of $1 \mathrm{~A} \mathrm{~g}^{-1}$.
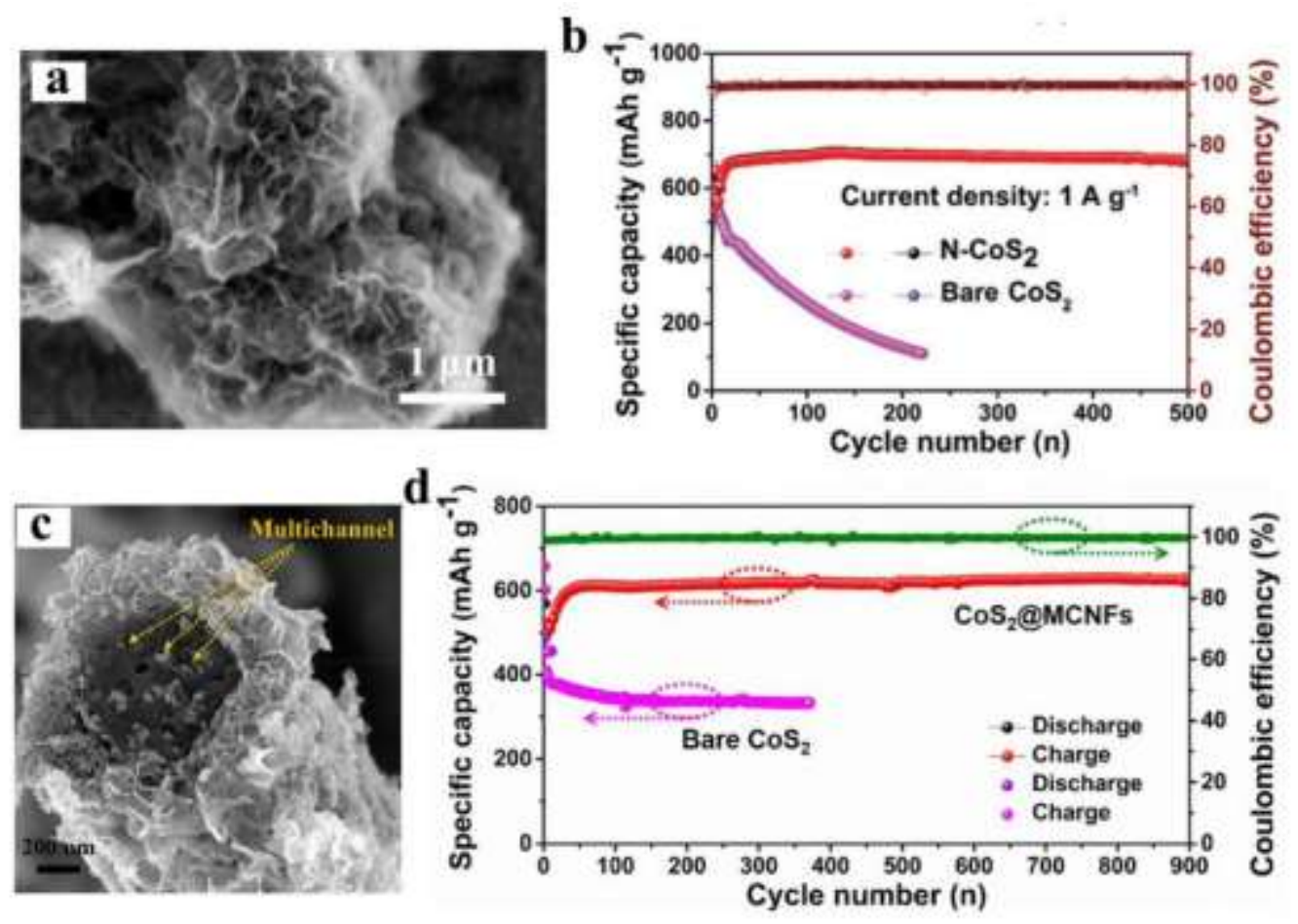

Fig. 8 (a) SEM images of the N-C/CoS 2 composites. (b) Cycling performance of N-C/CoS 2 and the bare $\mathrm{CoS}_{2}$ electrodes at $1 \mathrm{~A} \mathrm{~g}^{-1}$.[103] (c) High magnification SEM images of the $\mathrm{CoS}_{2} @ \mathrm{MCNFs}$ composites. (d) Cycling life testing of $\mathrm{CoS}_{2} @ \mathrm{MCNFs}$ electrode and bare $\mathrm{CoS}_{2}$ electrode.[104]

It has been pointed out that when using ether-based electrolyte, $\mathrm{CoS}_{2}$-based electrodes show both better cycling stability and rate capability, than with carbonate-based electrolyte.[108] Several factors causing this better performance have been proven, with some mechanistic 
similarities for Li-S systems. Firstly, a more stable SEI membrane can form in ether-based electrolyte, which means less consumption of electrolyte and sodium salt. Then, ether-based electrolytes have a better wettability with electrodes than carbonate-based electrolytes. Finally, faster charge-transfer kinetics can be observed in ether-based electrolytes.

\section{$3.3 \operatorname{CoS}$}

$\mathrm{CoS}$ is another type of cobalt chalcogenide, which has been regarded as another potential anode material for the alkaline ion battery.[109] It appears that almost all of the CoS investigated within the energy storage field is indexed to the hexagonal crystal phase with a $P 63 / \mathrm{mmc}$ space group. The corresponding crystal structure is shown in Fig 9.[110] Every crystal cell possesses two $\mathrm{Co}^{2+}$ ions and $\mathrm{S}^{2-}$ ions. Each $\mathrm{Co}^{2+}$ ion occupies the center site of octahedron with six $\mathrm{S}^{2-}$ ions coordinate it; the adjacent $\mathrm{CoS}_{6}$ octahedrons share edges and faces. As an anode material for sodium ion battery, $\mathrm{CoS}$ has a theoretical capacity of $588 \mathrm{mAh} \mathrm{g}^{-1}$. In a $\mathrm{Na}^{+}$ion intercalation process, each $\mathrm{CoS}$ will react with two $\mathrm{Na}^{+}$ions. Similarly with $\mathrm{CoS}_{2}$, this reaction can be divided into two steps, the insertion step $\left(\mathrm{CoS}+\mathrm{xNa}^{+}+\mathrm{xe}^{-} \rightarrow \mathrm{Na}_{\mathrm{x}} \mathrm{CoS}, \mathrm{x}<2\right)$ and the conversion step $\left(\mathrm{Na}_{\mathrm{x}} \mathrm{CoS}+(2-\mathrm{x}) \mathrm{Na}^{+}+(2-\mathrm{x}) \mathrm{e}^{-} \rightarrow \mathrm{Co}+\mathrm{Na}_{2} \mathrm{~S}\right)$. Generally, the conversion step takes place below 0.8 V. [111-113]

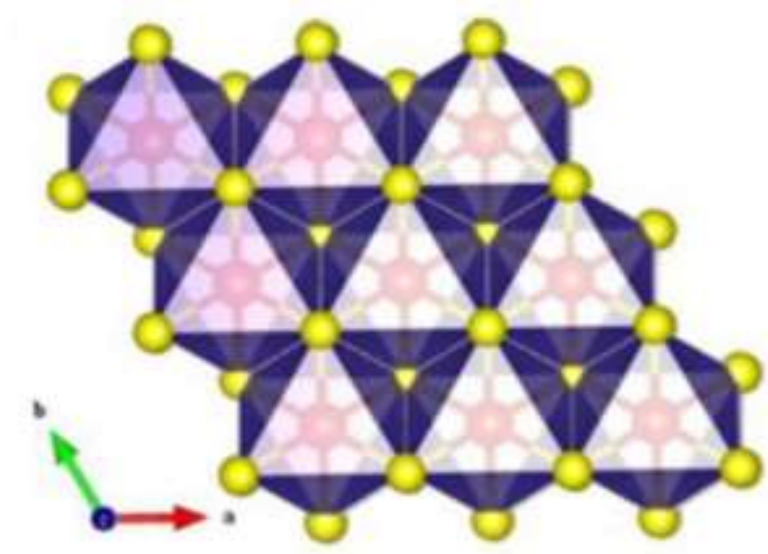

Fig. 9 Crystal structure of hexagonal CoS.[110]

It is well known that the conversion reaction faces similar challenges to other materials discussed previously such as volume expansion, low reversibility and so on.[114-119] Thus, there is no doubt that the conversion step has a remarkable influence upon the electrochemical 
performance of CoS. As can be seen in Fig. 10b[114], when the potential window is extended to 0.1-2.9 V, allowing the conversion step to dominate, more than $75 \%$ of initial capacity decayed after 500 cycles at $1 \mathrm{~A} \mathrm{~g}^{-1}$. In contrast, when the cut-off voltage was set to $0.6 \mathrm{~V}$ to avoid the conversion step, as shown in Fig. 10a, a high retention rate of $88 \%$ could be obtained over 1000 cycles at the same current density. However, although this potential window controlling strategy is highly effective, the capacity provided by conversion step will not be provided. Finally, if the CoS electrode is assembled in a full cell system, the overall reduction of the energy density within this device, will not provide a suitable energy storage platform. Thus, there is a vast requirement to develop methodologies that will alleviate the problems caused by the conversion step.

A method to overcome this destructive conversion step is to use a Co based MOF as a precursor to build porous carbon substrate. For example, through a facile calcination method within inert gas, CoS nanoparticles embedded into porous carbon rods were synthesized by Zhou et al.[110] In the optimized sample, the average size of CoS particles was $7 \mathrm{~nm}(7-\mathrm{CoS} / \mathrm{C})$. This ultrathin particle suffered more expansion stress than the larger particles with average size of 18.5 $\mathrm{nm}$ (18.5-CoS/C). As displayed in Fig. 10c, the composite electrode consisting of $7 \mathrm{~nm}$-sized CoS particles exhibits an improved cycling life than that those containing larger sized active material particles. Additionally, a smaller particle size can also shorten $\mathrm{Na}^{+}$ion diffusion path leading to an increased rate capability. These approaches confirms that the conductive host is important to alleviate increased material resistance from smaller particles with similar tap density to electrode formulations with larger particles, while nanoscaling ensures a better tolerance to volume expansion and accommodation of conversion mode products during cycling. 

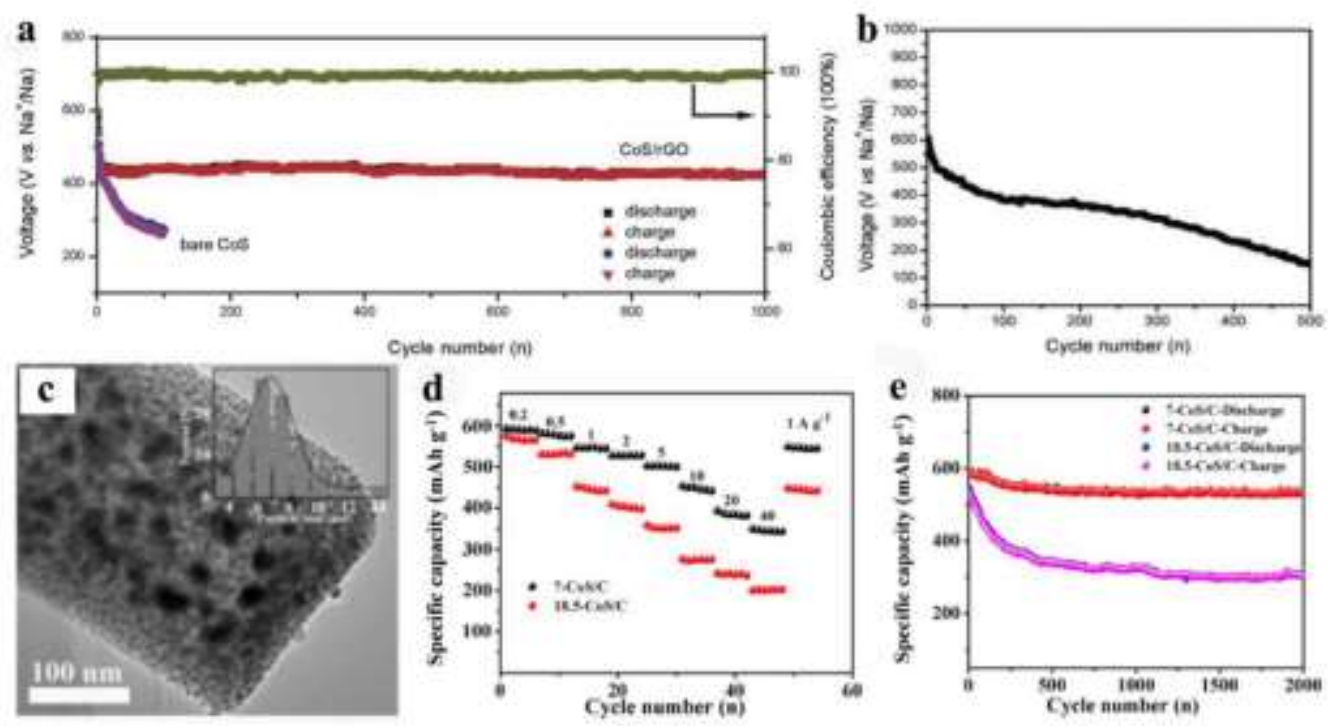

Fig. 10 (a) Cycling performance (left) and Coulombic efficiency (right) of the CoS@rGO composite at a current density of $1 \mathrm{~A} \mathrm{~g}^{-1}$ over a voltage window of 0.6-3.0 V. (b) Cycling performance of $\mathrm{CoS} / \mathrm{rGO}$ at a current density of $1 \mathrm{~A} \mathrm{~g}^{-1}$ over a potential window of 0.01-2.9 V.[114] (c) High-resolution TEM with inset of particle size distribution diagram for 7-CoS/C. (d) Rate capability and (e) cycling performance at a current density of $1 \mathrm{~A} \mathrm{~g} \mathrm{~g}^{-1}$ in the voltage range of $0.6-3$ $\mathrm{V}\left(v s . \mathrm{Na}^{+} / \mathrm{Na}\right)$ for $7-\mathrm{CoS} / \mathrm{C}$ and $18.5-\mathrm{CoS} / \mathrm{C}$ electrodes.[110]

The construction of a yolk-shell structure can also address the aforementioned problems. Recently, Mai's group reported a self-adaptive CoS@C with yolk-shell microsphere composite was obtained by $\mathrm{SiO}_{2}$-templated method.[120] Briefly, as shown in Fig. 11a, the silica and resorcinol formaldehyde (RF) was coated on the CoS precursor. After an annealing process, the resulting $\mathrm{SiO}_{2}$ particles were etched by $\mathrm{HF}$ and the yolk-shell structure was obtained. The resulting morphologies of the cycled samples were also investigated. The CoS micron spheres without carbon shells deteriorated after 10 cycles and were totally pulverized after 50 cycles. Nonetheless, the yolk-shell CoS@C composite can maintain its structural integrity even after 50 cycles. The gap-space was states as the reasons why this material could accommodate the volume expansion of the products during the conversion step ( $\mathrm{Co}$ and $\left.\mathrm{Na}_{2} \mathrm{~S}\right)$, with the carbon shell preventing the loss of active material. 


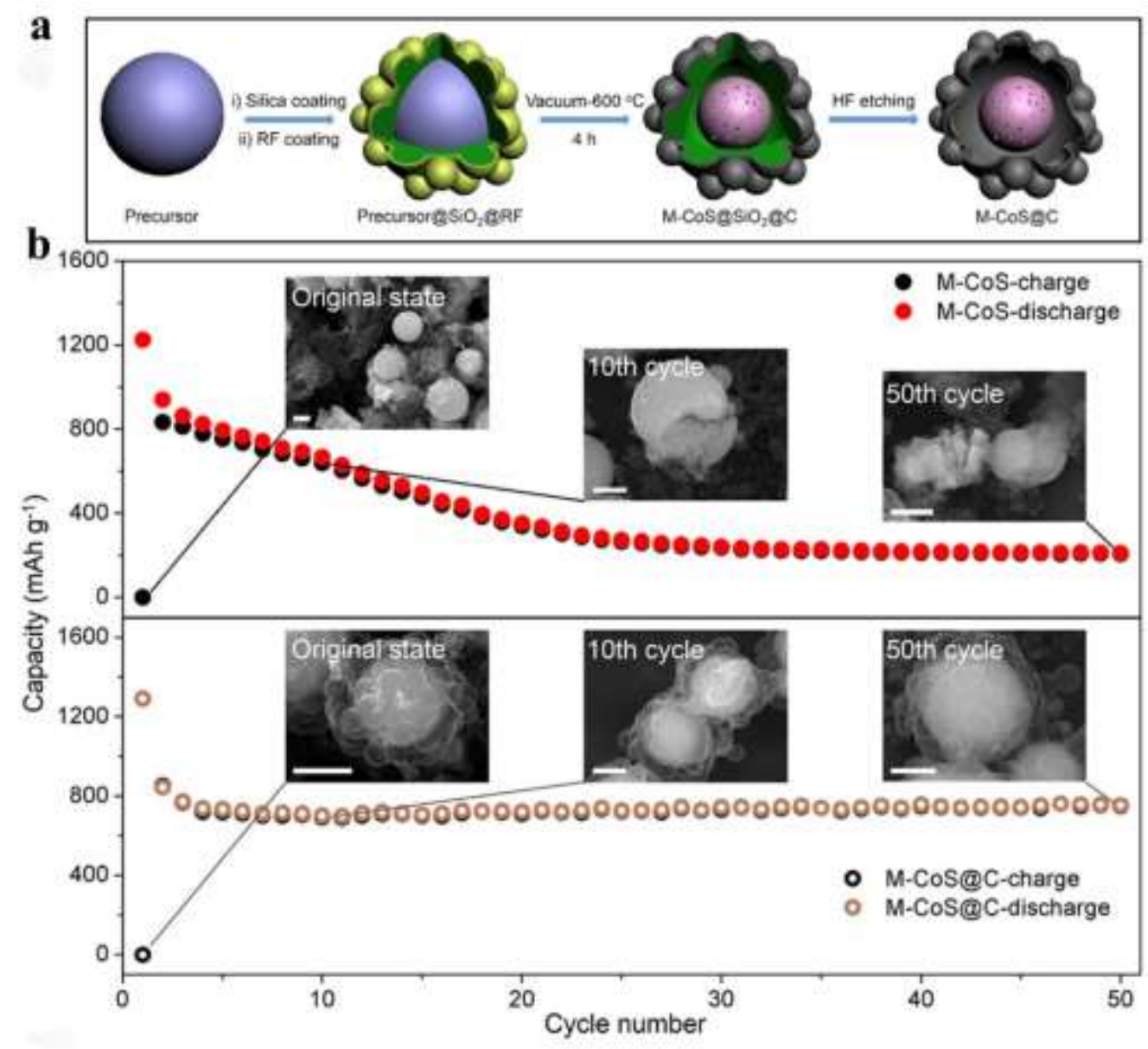

Fig. 11 (a) Schematic illustration of the synthesis of yolk-shell M-CoS@C. (b) The SEM images of the M-CoS and yolk-shell M-CoS@C at $0,10^{\text {th }}$ and $50^{\text {th }}$ cycle (full charge state) respectively, and their corresponding cycling performances at $1 \mathrm{~A} \mathrm{~g}^{-1}$. Scale bar, $1 \mu \mathrm{m} .[120]$

\section{Cobalt Selenide Anodes}

\section{$4.1 \mathrm{CoSe}_{2}$}

Generally, compared with other metal oxides and sulfides, metal selenides possess higher volumetric capacity and electrical conductivity, and have been routinely applied within SIBs.[121, 122] Generally, metal selenides have similar properties with metal sulfides, resulting in the wide range of investigations of $\mathrm{CoSe}_{2}$, as a promising anode for $\mathrm{SIBs}$. $\mathrm{CoSe}_{2}$ has two different phases, namely the trogtalite and hastite phases. The first belongs to an orthorhombic marcasite phase with a space group of Pnnm and the second is the cubic phase with a space group of Pa3. Both of these phases of $\mathrm{CoSe}_{2}$ have been studied as anode materials for SIBs.[123, 124] For example, the crystal structure of hastite phase is shown in Figure 12a, and, six Se anions coordinate to a $\mathrm{Co}^{2+}$ 
ion, which occupies the center site of the octahedron. The adjacent Se anions forms a $\mathrm{Se}_{2}{ }^{2-}$ anion via a covalent Se-Se bond.[123]

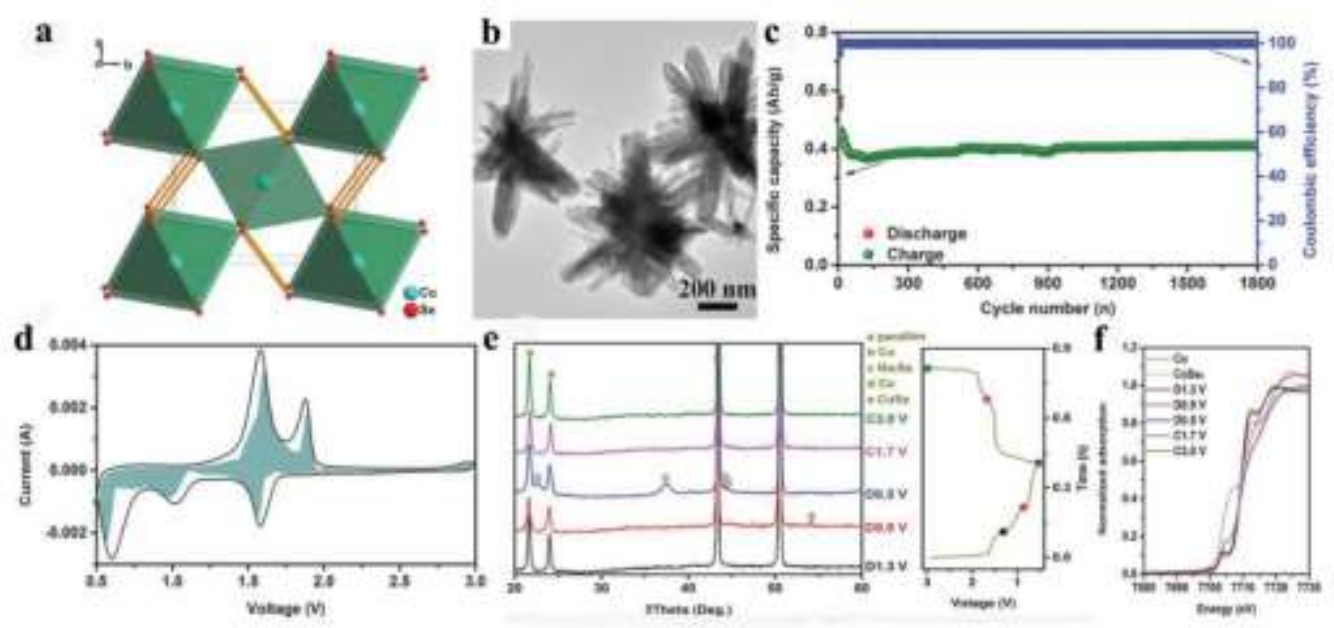

Fig. 12 (a) Crystal structure of the marcasite-type $\mathrm{CoSe}_{2}$. (b) TEM and (c) cycling life of the $\mathrm{CoSe}_{2}$ at a current rate of $1 \mathrm{~A} \mathrm{~g} \mathrm{~g}^{-1}$. CV curve with the pseudocapacitive fraction shown by the darkly cyan region at a scan rate of $1 \mathrm{mV} \mathrm{s}^{-1}$. (e) Reaction mechanism: ex situ XRD analysis of the $\mathrm{CoSe}_{2}$ electrodes at different charge-discharge states with the corresponding charge-discharge curve and parafilm was used to protect the $\mathrm{CoSe}_{2}$ electrodes when testing XRD. (f) Near-edge X-ray absorption spectroscopy of the $\mathrm{CoSe}_{2}$ electrodes at different cycling states and the reference Co and $\mathrm{CoSe}_{2} \cdot[123]$

$\mathrm{Ou}$ and co-workers focused on the mechanism for $\mathrm{Na}^{+}$ion intercalation reaction with $\mathrm{CoSe}_{2}$. It has been proven that this electrochemical reaction can be divided into three steps and CoSe forms as an intermediate product. In detail, the three steps are as follows[125]:

$$
\begin{array}{ll}
\text { Intercalation step: } & \mathrm{CoSe}_{2}+\mathrm{xNa}^{+}+\mathrm{xe}^{-} \rightarrow \mathrm{Na}_{\mathrm{x}} \mathrm{CoSe}_{2} \quad(\mathrm{x}<2,>1.0 \mathrm{~V}) \\
\text { Transition step: } & \mathrm{Na}_{\mathrm{x}} \mathrm{CoSe}_{2}+(2-\mathrm{x}) \mathrm{Na}^{+}+(2-\mathrm{x}) \mathrm{e}^{-} \rightarrow \mathrm{Na}_{2} \mathrm{Se}+\mathrm{CoSe}(1.0-0.8 \mathrm{~V}) \\
\text { Conversion step: } & \mathrm{CoSe}+\mathrm{yNa}^{+}+\mathrm{ye}^{-} \rightarrow \mathrm{Na}_{2} \mathrm{Se}+\mathrm{Co}^{0}(0.8-0.01 \mathrm{~V})
\end{array}
$$

Based upon this electrochemical reaction with four electrons, $\mathrm{CoSe}_{2}$ exhibits a theoretical capacity of $494 \mathrm{mAh} \mathrm{g}^{-1}$. However, as with $\mathrm{CoS}_{2}$, the application of $\mathrm{CoSe}_{2}$ is hindered by its poor cycling performance due to the volume change and structural pulverization.[126, 127]

Chen's group synthesized a kind of urchin-like $\mathrm{CoSe}_{2}$, which consists of multiple nanorods as 
shown in Fig. 12b,[123] with pseudocapacitive behaviors (Fig. 12d) that can lead to a stable cycling life. This material shows a high reversible capacity of $410 \mathrm{mAh} \mathrm{g}^{-1}$ after 1800 cycles, at a current density of $1 \mathrm{~A} \mathrm{~g}^{-1}$, over a potential window of 0.5-3.0 $\mathrm{V}$ as displayed in Fig. 12c. Upon incorporation into a $\mathrm{Na}_{3} \mathrm{~V}_{2}\left(\mathrm{PO}_{4}\right)_{3} / \mathrm{CoSe}_{2}$ full cell, the urchin-like $\mathrm{CoSe}_{2}$ still exhibits a high capacity of $380 \mathrm{mAh} \mathrm{g}^{-1}$. However, there is a huge capacity loss between the 1st and 2nd cycles, which could be due to the irreversible formation of SEI. To further understand this phenomenon, as exhibited in Fig. 12e-f, ex situ XRD analysis and near-edge X-ray absorption spectroscopy determined that, after the first discharge process, even upon charging to $3.0 \mathrm{~V}$, the anode material did not return to its original pristine state, as some $\mathrm{Na}^{+}$ions were not extracted from the anode material. Thus, upon subsequent cycles, the reversible electrochemical reaction starts and ends with the state of $\mathrm{Na}_{\mathrm{x}} \mathrm{CoSe}_{2}$, which unavoidably hinders the capacity of the anode material.

Another methodology that has been considered is the synthesis of a novel type of $\mathrm{CoSe}_{2} @ \mathrm{C}$ bridged with carbon nanotubes $\left(\mathrm{CoSe}_{2} @ \mathrm{C} / \mathrm{CNTs}\right)$ reported by Qiu et al..[127] As can be seen in Fig 13, the precursor, ZIF 67, was annealed in $\mathrm{H}_{2} / \mathrm{Ar}$ mixed gas and the $\mathrm{Co}^{2+}$ was reduced to form Co metallic nanoparticles. These metal particulates act as a catalyst promoting the formation of the carbon nanotubes. In this hierarchical structure, the CNT can construct a cross-linked conductive network and prevent the agglomeration of the active material. This composite demonstrates a high reversible specific capacity of about $470 \mathrm{mAh} \mathrm{g}^{-1}$ at a current density of $0.2 \mathrm{~A} \mathrm{~g}^{-1}$. After 1000 cycles, a superior capacity retention closing to $100 \%$ can be observed (calculated from the 70 th cycles). 

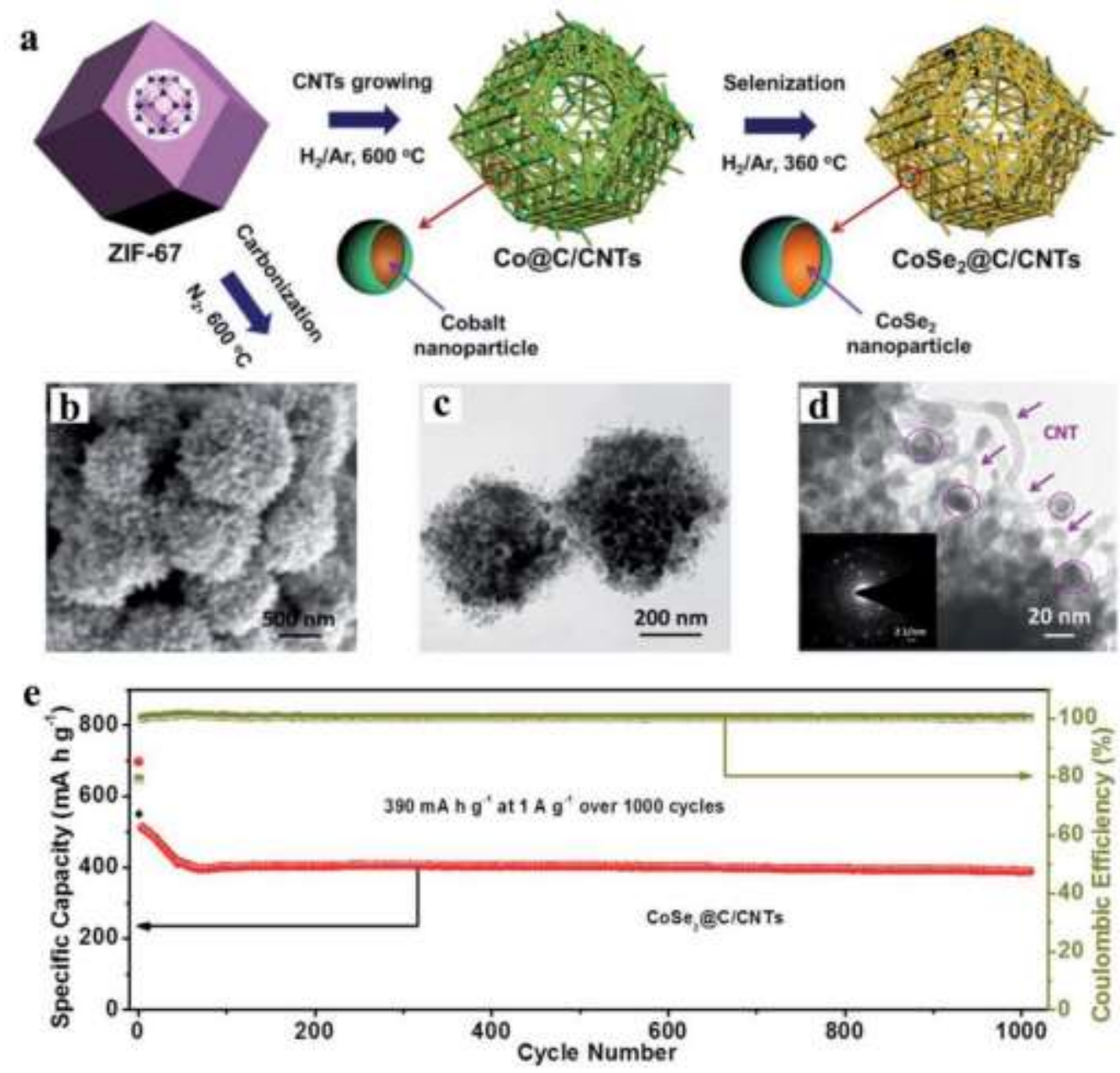

Fig. 13 (a) Synthetic processes of the CoSe $e_{2} @$ C/CNTs and CoSe $2 @$ GC. (b) FESEM images and (c) TEM images exhibiting the polyhedral $\mathrm{CoSe}_{2} @ \mathrm{C} / \mathrm{CNTs}$ integrated with tangled CNTs and carbon-coated $\mathrm{CoSe}_{2}$ nanospheres; (d) TEM image of the CNTs (shown by purple arrows) on $\mathrm{CoSe}_{2}$ particle surface; the SEAD patterns (inset) suggest the polycrystalline structure of $\mathrm{CoSe}_{2}$ nanospheres in the hybrid. (e) Long-life cyclability of the $\mathrm{CoSe}_{2} @ \mathrm{C} / \mathrm{CNTs}$ anode.[127]

The structural design of coating other kind of metal sulfides to form heterostructure has been also applied for optimizing the electrochemical performance of $\operatorname{CoSe}_{2} \cdot[128,129]$ Through a facile synthesis route combining hydrothermal coating and selenization processes, $\mathrm{CoSe}_{2}$ particles with $\mathrm{MoSe}_{2} / \mathrm{C}$ shells were developed as a composite $\left(\mathrm{CoSe}_{2} \subset \mathrm{MoSe}_{2} / \mathrm{C}\right)$.[130] This $\mathrm{MoSe}_{2} / \mathrm{C}$ hybrid shell was reported to simultaneously enhance the transition of both ions and electrons, alleviating the volume change during alkaline ion insertion/extraction processes. Combining this with a capacitive contribution, this composite shows a specific capacity of $450 \mathrm{mAh} \mathrm{g}^{-1}$ over 100 cycles 
at $0.1 \mathrm{~A} \mathrm{~g} \mathrm{~g}^{-1}$, and maintains more than $300 \mathrm{mAh} \mathrm{g}^{-1}$ capacity at $1 \mathrm{~A} \mathrm{~g}^{-1}$ after 200 cycles, respectively.

\subsection{Other cobalt selenides}

Recently, Chen's group reported the utilization of porous $\mathrm{Co}_{0.85} \mathrm{Se}$ ultrathin nanosheets anchoring on rGO composite as an anode for SIB. The morphology of as prepared $\mathrm{Co}_{0.85} \mathrm{Se}$ nanosheets is shown in Fig 14a.[131] As can be seen in Fig. 14b-c, this composite shows superior capability and stable cycling life over 800 cycles at $1 \mathrm{~A} \mathrm{~g}^{-1}$. This hierarchical nanostructure can provide enough active sites for $\mathrm{Na}^{+}$ions adsorption and reserve space to accommodate the volume change. Importantly, the unequal content of $\mathrm{Co}$ and $\mathrm{Se}$ elements in $\mathrm{Co}_{0.85} \mathrm{Se}$ leads to the formation of defects. As shown in Fig. 14d-e, the band gap calculation by using density function theory (DFT), shows that the $\mathrm{Co}_{0.85} \mathrm{Se}$ has a narrower band gap $(0.68 \mathrm{eV})$ than that of the CoSe $(1.36 \mathrm{eV})$, meaning an enhanced electronic conductivity. These defects also provide suitable $\mathrm{Na}^{+}$ion diffusion pathways, which can lead to a lower migration energy barriers of $\mathrm{Co}_{0.85} \mathrm{Se}$ than for CoSe as displayed in Fig. f-g, respectively. Additionally, the possible $\mathrm{Na}^{+}$ion diffusion trajectories in above two kinds of materials are shown in Fig. 14h. The bond length of $\mathrm{Co}-\mathrm{Se}$ in $\mathrm{Co}_{0.85} \mathrm{Se}$ is longer than that in $\mathrm{CoSe}$, leading to faster reaction kinetics for the $\mathrm{Co}_{0.85} \mathrm{Se}$ conversion to Co and $\mathrm{Na}_{2} \mathrm{Se}$.

a
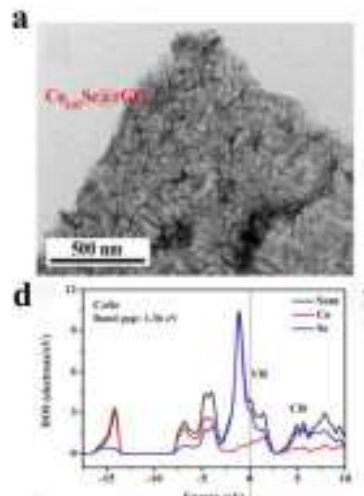

e

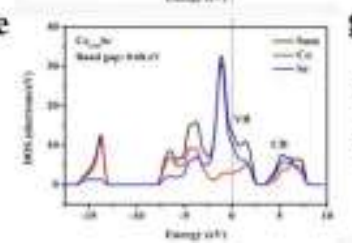

b
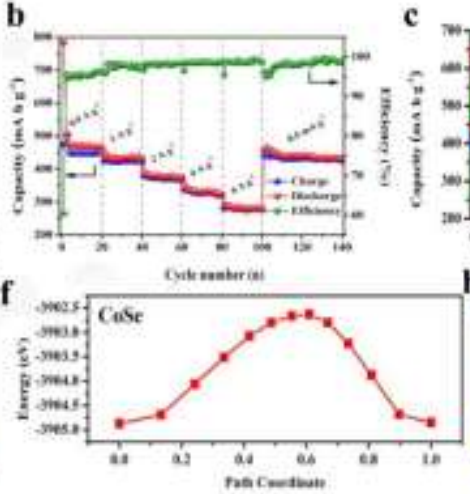

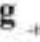

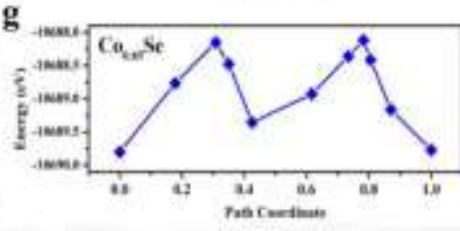

c
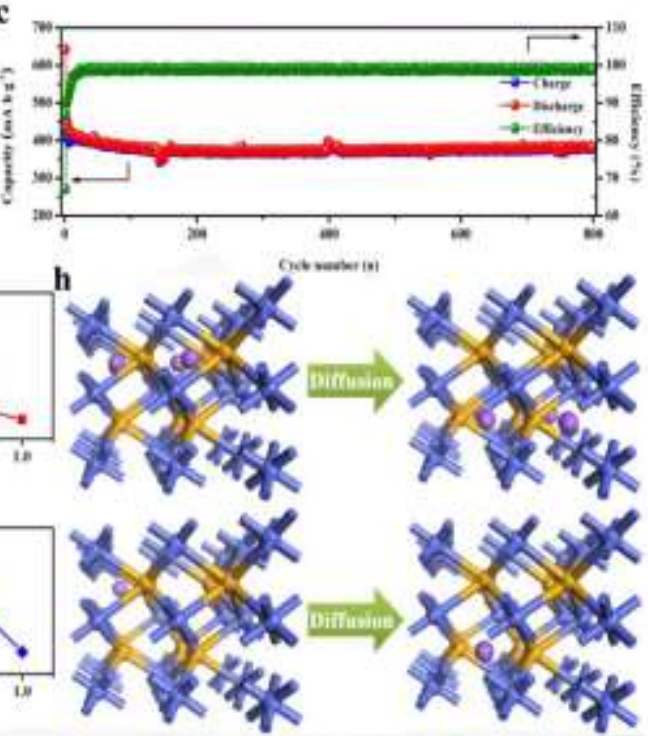

Fig. 14 (a) TEM images of $\mathrm{Co}_{0.85} \mathrm{Se} \mathrm{NSs} @$ rGO. (b) Rate performance at different current densities and (c) long-cycling performance at $1 \mathrm{~A} \mathrm{~g}^{-1}$ for $\mathrm{Co}_{0.85} \mathrm{Se} \mathrm{NSs} @ \mathrm{rGO}$ electrode. (d-e) DOS and 
PDOS spectra of CoSe and $\mathrm{Co}_{0.85} \mathrm{Se}$. (f-g) The calculated migration energy barriers of the single $\mathrm{Na}^{+}$ions along the described paths. (h) Possible $\mathrm{Na}^{+}$ion diffusion trajectories in CoSe (upper schematics) and $\mathrm{Co}_{0.85} \mathrm{Se}$ (lower schematics) through the vacancy site.[131]

Another $\mathrm{Co}_{0.85} \mathrm{Se} /$ graphene composite has been reported by Zhou's group, as a binder-free anode electrode for alkaline ion battery.[132] As can be seen in Figure 15, the $\mathrm{Co}_{0.85} \mathrm{Se}$ nanosheets anchored on graphene stably and this "sheet-on-sheet" nanostructure with strong interfacial interaction can self-assemble to form a flexible film electrode without any conductive additive and binder. It is believed that the strong interfacial interaction between different parts of the composite can effectively enhance the electron transfer. Graphene can not only play a role of conductive matrix, but also protect the $\mathrm{Co}_{0.85} \mathrm{Se}$ from agglomeration after the charge-discharge test. Besides this, the binder-free strategy can improve the volumetric specific capacity of this electrode. When applied to SIBs, this novel electrode exhibits a preferred stable cycling performance and better rate capability than pure $\mathrm{Co}_{0.85} \mathrm{Se}$ nanosheet electrode.
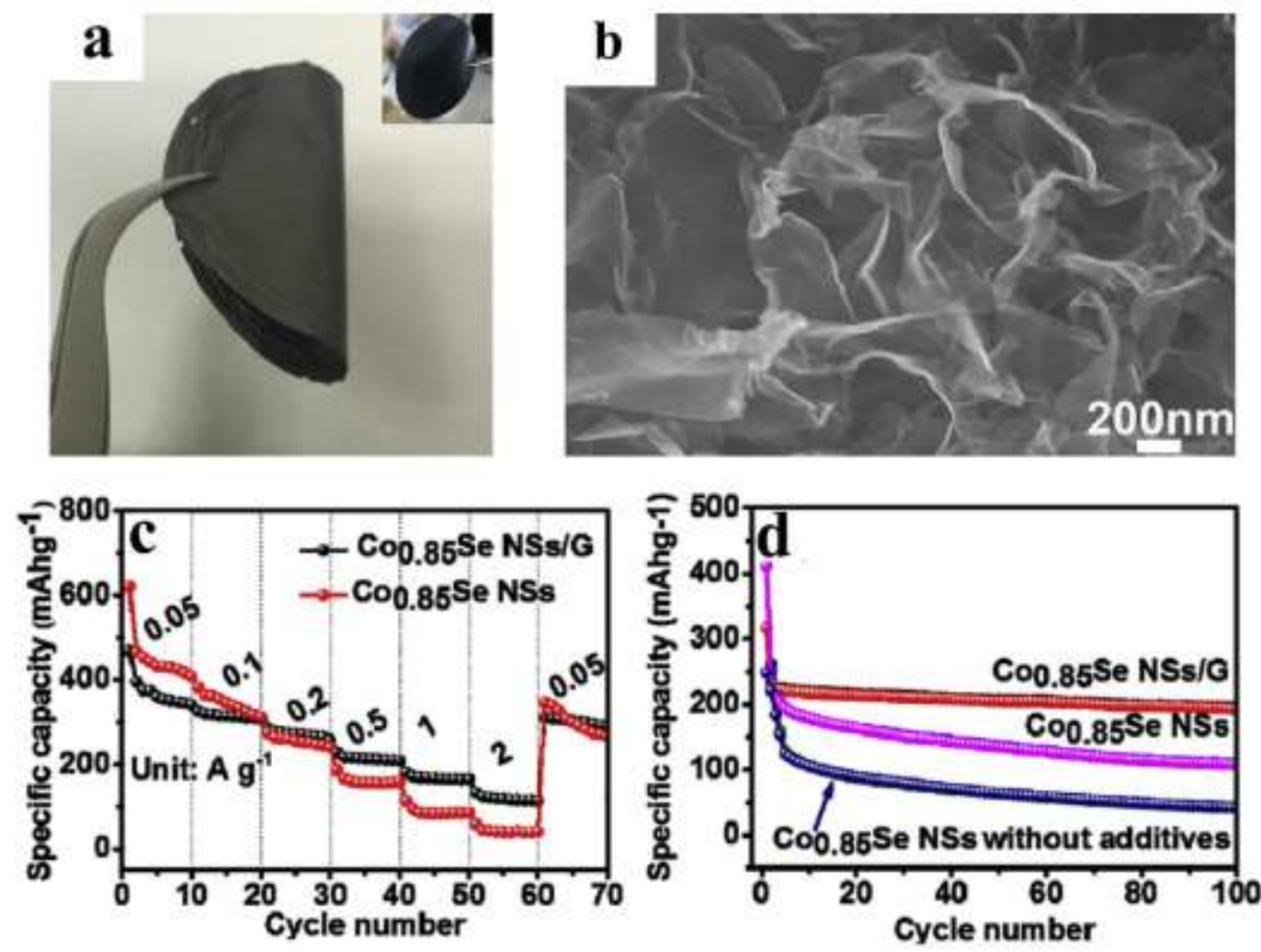

Fig. 15 (a) Optical images of the $\mathrm{Co}_{0.85} \mathrm{Se} \mathrm{NSs} / \mathrm{G}$ film with the inset of $\mathrm{Co}_{0.85} \mathrm{Se} \mathrm{NSs} / \mathrm{GO}$ film. (b) SEM images of $\mathrm{Co}_{0.85} \mathrm{Se}$ NSs. (c) Sodium storage rate performance of the $\mathrm{Co}_{0.85} \mathrm{Se}$ NSs and the 
$\mathrm{Co}_{0.85} \mathrm{Se} \mathrm{NSs} / \mathrm{G}$ film. (d) Cyclic properties of the $\mathrm{Co}_{0.85} \mathrm{Se}$ NSs with and without the addition of a binder and conducting additives and of the $\mathrm{Co}_{0.85} \mathrm{Se} / \mathrm{G}$ film at a current density of $0.5 \mathrm{~A} \mathrm{~g}^{-1}$.[132]

\section{5. $\mathrm{Na}_{0.7} \mathrm{CoO}_{2}$ SIB Cathodes}

Sodium cobaltates, $\mathrm{Na}_{\mathrm{x}} \mathrm{CoO}_{2}(0.5 \leq \mathrm{x} \leq 1)$, are a significant cathode material for SIBs. Researchers have paid much attention to this type material for two main reasons.[133-135] $]^{133-135}$ Firstly, several transition-metal oxides cathodes for SIBs, such as $\mathrm{Na}_{\mathrm{x}} \mathrm{VO}_{2}, \mathrm{Na}_{\mathrm{x}} \mathrm{CrO}_{2}, \mathrm{Na}_{\mathbf{x}} \mathrm{MnO}_{2}$, several sodium cobaltates, $\mathrm{Na}_{\mathrm{x}} \mathrm{CoO}_{2}(0.5 \leq \mathrm{x} \leq 1)$, have been routinely examined for the electrochemical sodium intercalation as early as the early 1980s.[136] Secondly, the success of $\mathrm{LiCoO}_{2}$ as the cathode for lithium-ion battery, also promotes research on $\mathrm{Na}_{\mathrm{x}} \mathrm{CoO}_{2}$ for SIBs.[137]

$\mathrm{Na}_{\mathrm{x}} \mathrm{CoO}_{2}$ has a layered structure that can be described as OCONOCON..., where the $\mathrm{O}$ represents oxygen, $\mathrm{C}$ represents cobalt and $\mathrm{N}$ represents sodium. According to the various sodium coordination, there are four different phases that can be identified within the sodium composition range from 0.5 to $1 .{ }^{8}$ Following the traditional nomenclature, these four phases are denoted as $\mathrm{O}$, $\mathrm{O}^{\prime} 3, \mathrm{P}^{\prime} 3$ and $\mathrm{P} 2$ phases. Briefly, $\mathrm{O}$ is the octahedral coordination and $\mathrm{P}$ represents the trigonal prismatic coordination of the sodium ions; the number two (2) or three (3) implies the number of distinguishable sodium layers within the structure. These various phases can be obtained by controlling the sodium concentration. Specifically, $\mathrm{NaCoO}_{2}$ is an $\mathrm{O} 3$ structure, $\mathrm{Na}_{0.77} \mathrm{CoO}_{2}$ is an $\mathrm{O}^{\prime} 3$ structure, $\mathrm{Na}_{0.64} \leq \mathrm{x} \leq_{0.77} \mathrm{CoO}_{2}$ is a $\mathrm{P} 2$ structure and $\mathrm{Na}_{0.55} \leq \mathrm{x} \leq_{0.6} \mathrm{CoO}_{2}$ is a $\mathrm{P}^{\prime} 3$ structure, respectively. Various crystal structures lead to differing electrochemistry and electrochemical performances. For example, the O3-phase cathode will transform into $\mathrm{O}^{\prime} 3$ or $\mathrm{P}^{\prime} 3$ phase. If the electrochemical reaction starts with the $\mathrm{O}^{\prime} 3$ or $\mathrm{P}^{\prime} 3$ phase, the value of ' $\mathrm{x}$ ' can increase and the $\mathrm{O} 3$ phase material is always obtained, as shown in Fig. 16a. Many previous studies reported that the phase transition between the above three phases can easily take place at room temperature.[137, $138]$

In contrast, when the electrochemical reaction starts with the P2 phases, the pristine structure can be preserved over the whole electrochemical process, as displayed in Fig. 16b.[139] Although this type of sodium cobaltate also undergoes a complex electrochemical reaction, the multiple plateaus upon charge-discharge are caused by the redistribution of $\mathrm{Na}^{+}$during 
intercalation-deintercalation process, not by the phase transitions. As a result, an improved structural stability leads to an overall better electrochemical performances. As far back as 1981, Delmas and co-workers ${ }^{138}$ found that the $\mathrm{P} 2$ phase sodium cobaltates possess the highest capacity $\left(\sim 95 \mathrm{mAh} \mathrm{g}^{-1}\right)$ among the different types of sodium cobaltates. Besides, P2 phases offer longer cycle life and higher energy efficiency. Thus, P2 type sodium cobaltates have attracted much attention and have been regularly studied. In the following paragraphs in this section, P2 type sodium cobaltates will be discussed in detail.

\section{a}

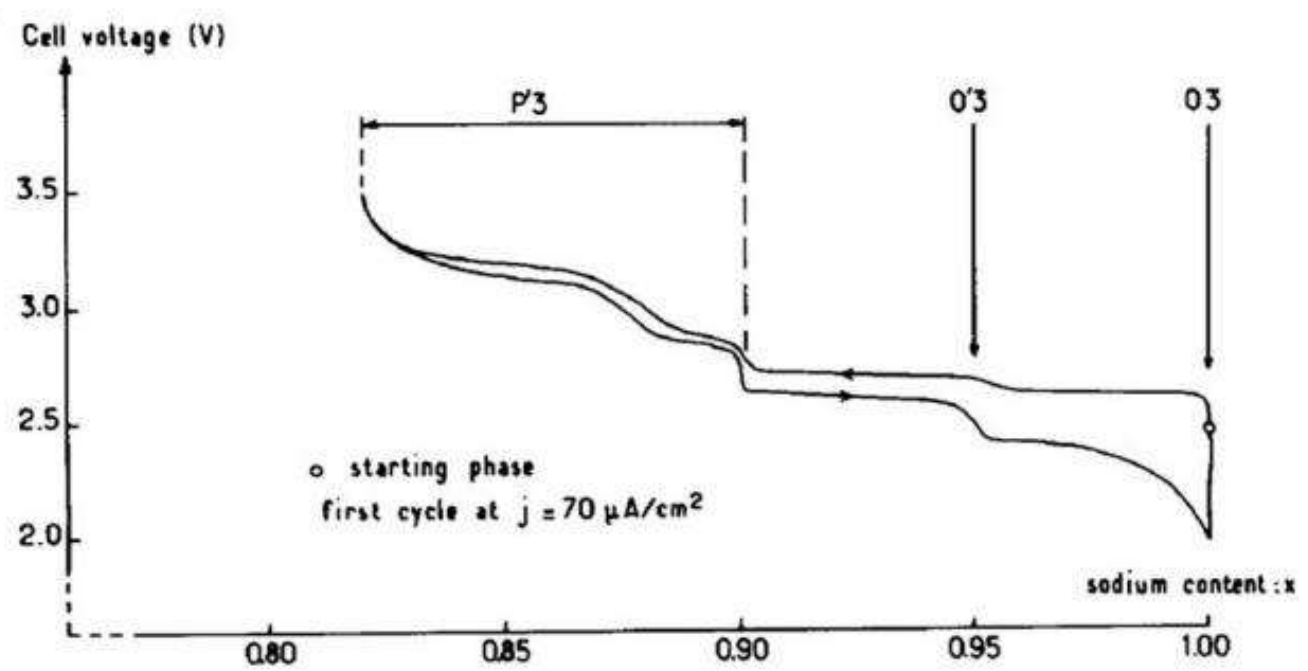

b

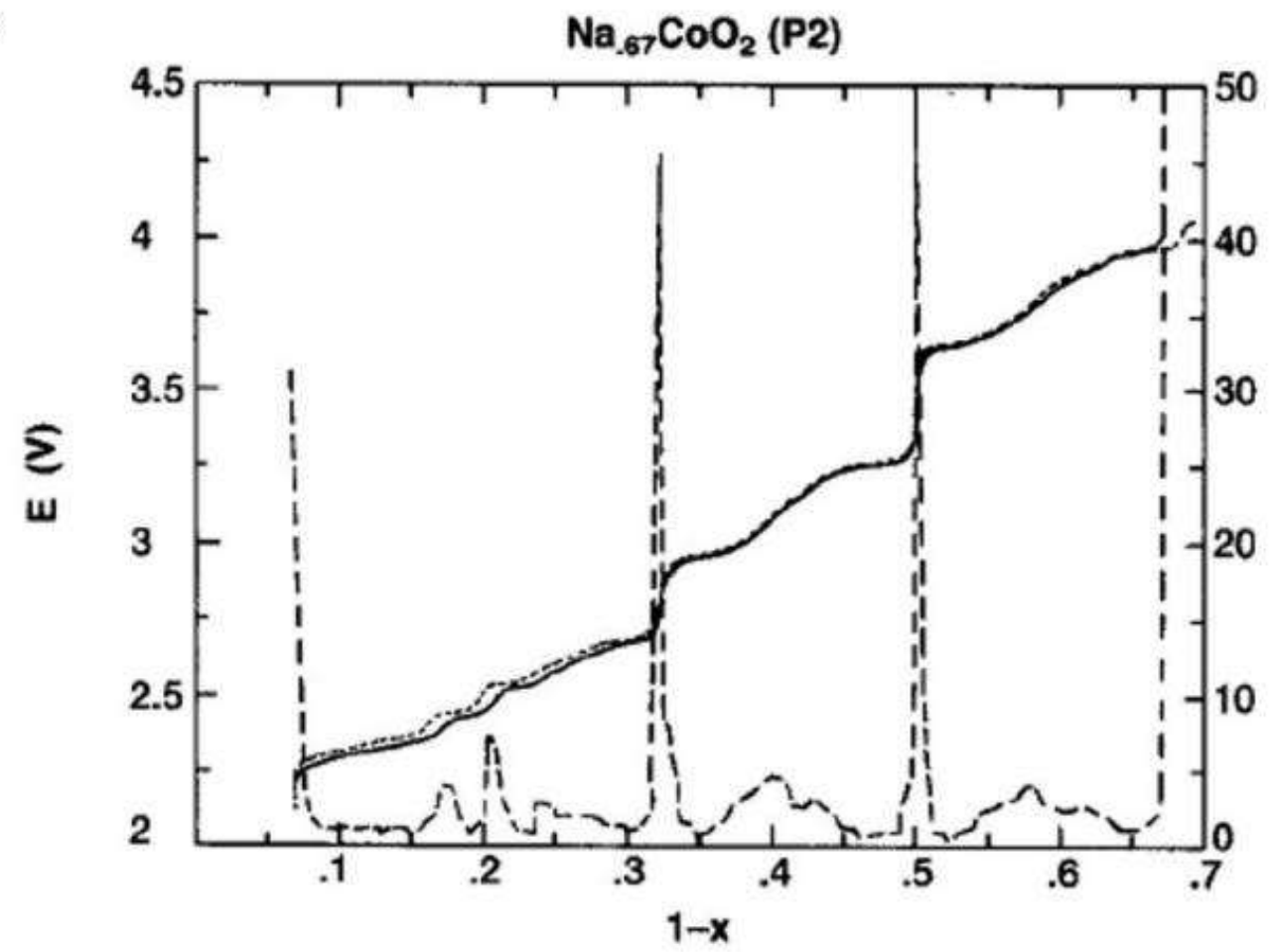


Fig. 16 (a) Emf composition curve obtained from $\mathrm{NaCoO}_{2}(\mathrm{O} 3) \cdot{ }^{138}$ (b) Open-circuit potential vs. composition for $\mathrm{P} 2-\mathrm{Na}_{067} \mathrm{CoO}_{2}$ during ion intercalation (solid curve) and deintercalation (dotted curve).[139]

To understand the electrochemical behaviour of $\mathrm{P} 2-\mathrm{Na}_{\mathrm{x}} \mathrm{CoO}_{2}$, the materials with different $\mathrm{Na}^{+}$compositions of were investigated systematically. Three main factors cause the cationic redistribution, including the electrostatic repulsion between $\mathrm{Na}^{+}$ion in different planes, the repulsion between $\mathrm{Na}^{+}$and $\mathrm{Co}^{3+}$ through the common face of different polyhedra and the electronic interaction in the Co layer. The schematic of cationic redistribution in $\mathrm{P} 2-\mathrm{Na}_{\mathrm{x}} \mathrm{CoO}_{2}$ is described in Fig. 17. The experimental result shows that the distribution of cationic ions has a significant impact on the electronic properties. Even a slight deviation (about $1 \%$ or $2 \%$ ) can form a new distribution of the $\mathrm{Na}^{+}$ions. Thus, the investigation of $\mathrm{P} 2-\mathrm{Na}_{\mathrm{x}} \mathrm{CoO}_{2}$ materials and their electrochemical performances is varied and interesting.[137]

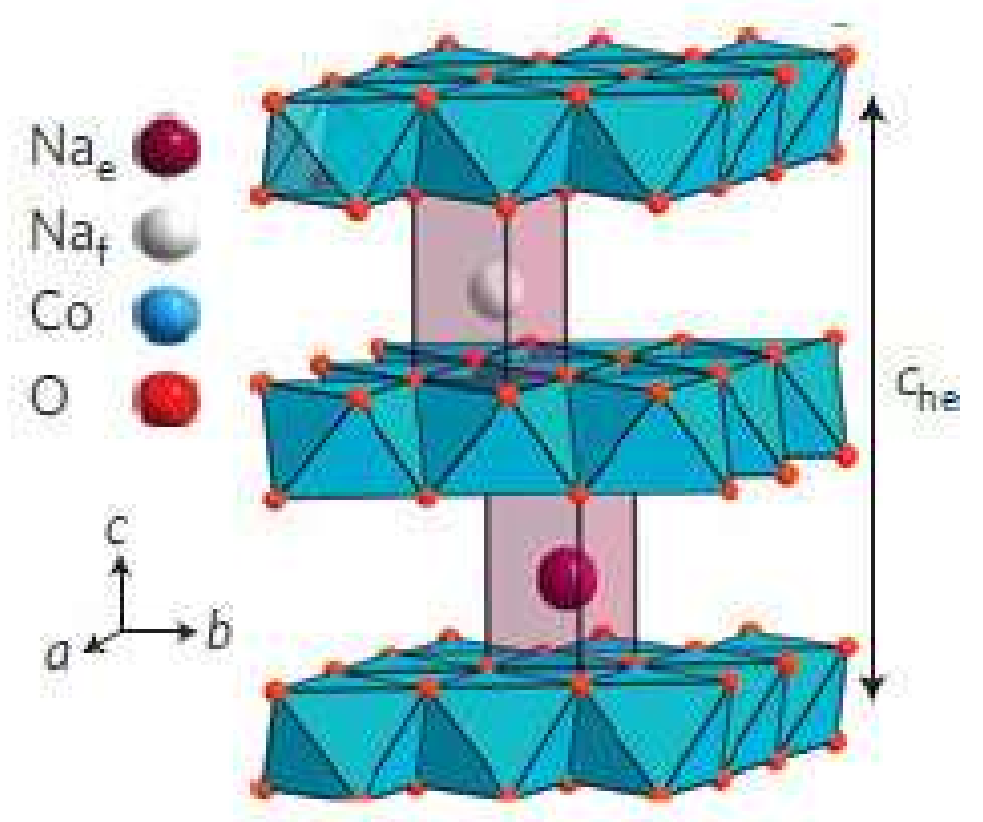

Fig. $17 \mathrm{Na}^{+} /$vacancy ordering in the interslab space of the lamellar structure of $\mathrm{P} 2-\mathrm{Na}_{\mathrm{x}} \mathrm{CoO}_{2}$ phases.[137]

As cathode material for SIB, the main disadvantage of $\mathrm{P} 2-\mathrm{Na}_{\mathrm{x}} \mathrm{CoO}_{2}$ is its poor cycling performance.[140] $]^{140}$ To solve this problem, several methods have been introduced such as morphology controlling, introduction of conductive substrate and cation doping. Recent work by 
Lou's group proved that regular morphology and microsize can prolong the cycling life and improve the volumetric energy density of $\mathrm{Na}_{0.7} \mathrm{CoO}_{2} \cdot[141]$ Such $\mathrm{Na}_{0.7} \mathrm{CoO}_{2}$ was synthesized by a facile strategy. As shown in Fig. 18, regular sized $\mathrm{CoCO}_{3}$ was used as the precursor, with the final product, regular- $\mathrm{Na}_{0.7} \mathrm{CoO}_{2}$ (r-NCO), maintaining a spherical morphology with a size of about 5 $\mu \mathrm{m}$. Between the operating voltage range of 2.0-3.8 V $\left(v s . \mathrm{Na} / \mathrm{Na}^{+}\right)$, this material offers a high specific capacity of $125 \mathrm{mAh} \mathrm{g}^{-1}$ at $0.04 \mathrm{C}$ (about $5 \mathrm{~mA} \mathrm{~g}^{-1}$ ). After 300 cycles, at $0.4 \mathrm{C}, 86 \%$ capacity is preserved for the regular $\mathrm{Na}_{0.7} \mathrm{CoO}_{2}$, which is remarkably higher than that of the irregular version (only a low capacity retention of $46 \%$ after 200 cycles can be observed for irregular $\mathrm{Na}_{0.7} \mathrm{CoO}_{2}$ ). Even at a large rate of $16 \mathrm{C}$ (about $2 \mathrm{~A} \mathrm{~g}^{-1}$ ), regular $\mathrm{Na}_{0.7} \mathrm{CoO}_{2}$, still demonstrates a high specific capacity of $64 \mathrm{mAh} \mathrm{g}^{-1}$, presenting excellent rate capability.

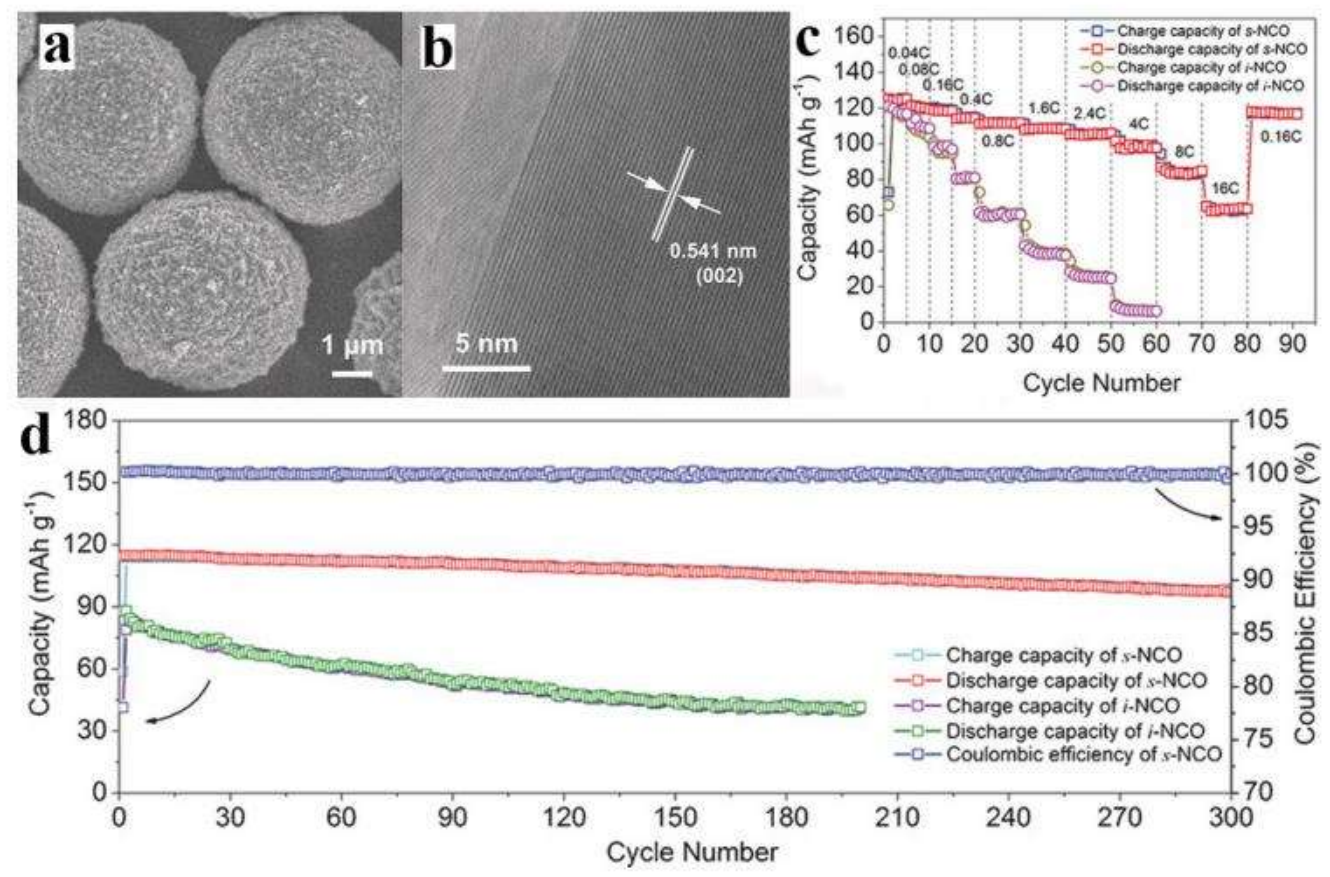

Fig. 18 (a) FESEM images and (b) HRTEM image of $\mathrm{P} 2-\mathrm{Na}_{0.7} \mathrm{CoO}_{2}$ microspheres. (c) Rate performance of s-NCO and irregular-NCO (i-NCO), and (d) Cycling performance of s-NCO and i-NCO at a current rate of $0.4 \mathrm{C}$ and the corresponding Coulombic efficiency of s-NCO. (Note: $\left.1 \mathrm{C}=125 \mathrm{mAh} \mathrm{g}^{-1}.\right)[141]$

Nanocrystallization is another effective strategy to improve the electrochemical performance of electrode materials. Engineering $\mathrm{Na}_{0.7} \mathrm{CoO}_{2}$ arrays upon $\mathrm{Ni}$ foam can control the size and morphology of this sodium cobaltates.[142] As shown in Fig. 19, open architecture $\mathrm{Na}_{0.7} \mathrm{CoO}_{2}$ 
nanosheets can orderly grow on Ni foam. This composite shows a high areal capacity of $1.16 \mathrm{mAh}$ $\mathrm{cm}^{-2}$ at $1 \mathrm{C}$, with a prolonged cycling life being obtained. More than $50 \mathrm{mAhg}^{-1}$ capacity can be preserved after 1100 cycles, at $6 \mathrm{C}$. Furthermore, at a larger rate of $15 \mathrm{C}$, a capacity of 57.8 $\mathrm{mAhg}^{-1}$ maintains. However, although the Ni foam substrate can bring significant advantages, such as binder free, high conductivity, open ion diffusion pathway, it will also reduce the energy density because Ni does not offer capacity.
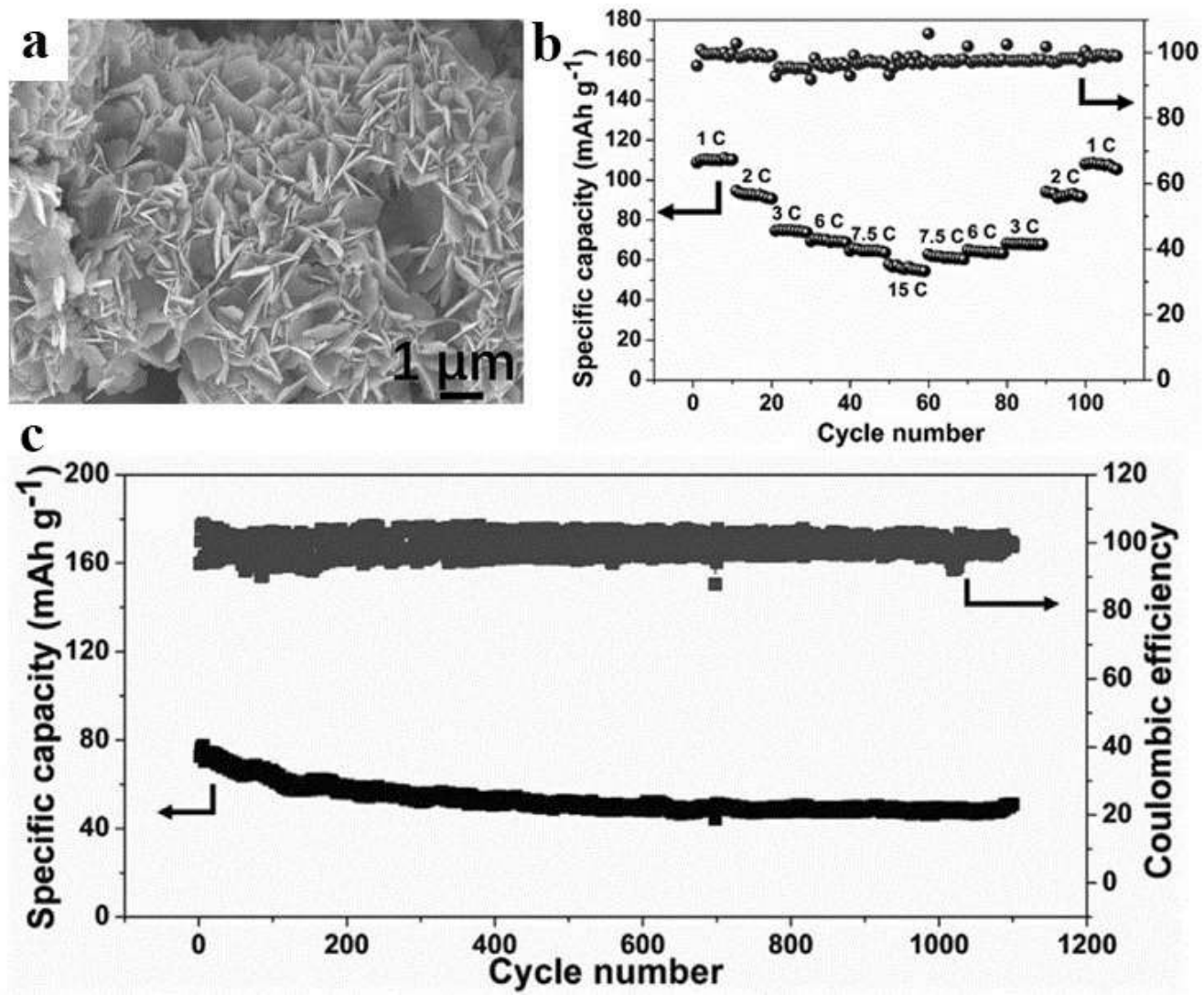

Fig. 19 (a) SEM images of $\mathrm{Na}_{0.7} \mathrm{CoO}_{2}$ arrays. (b) Rate performance at various current rates and Cycling performance of the $\mathrm{Na}_{0.7} \mathrm{CoO}_{2}$ electrode at a current rate of 6 C.[142]

It is believed that the cationic substitution improves the cycling life due to the suppression of the $\mathrm{Na}^{+} /$vacancy ordering condition.[143-145] Theoretical calculation results suggest that the $\mathrm{P} 2-\mathrm{Na}_{\mathrm{x}} \mathrm{Ni}_{\mathrm{y}} \mathrm{Co}_{1-\mathrm{y}} \mathrm{O}_{2}$ cathodes $(\mathrm{x}=0.66$ or 0.75 , and $0 \leq \mathrm{y} \leq 0.33)$ are thermodynamically stable or metastable.[146] Therefore, a new type of P2-type layered transition metal oxide, $\mathrm{Na}_{0.75} \mathrm{Ni}_{0.22} \mathrm{Co}_{0.78} \mathrm{O}_{2}$, has been synthesized by Bianchini and co-workers. The introduction of nickel can increase the capacity and raise the average discharge voltage to $\sim 3 \mathrm{~V}$. However, the cycling performance and Coulombic efficiency of this material should be further optimized. 
Further investigations by Kang et al. have considered the effect of titanium substitution upon the P2- $\mathrm{Na}_{\mathrm{x}} \mathrm{CoO}_{2}$.[147] However, the content of $\mathrm{Ti}$ should not be higher than $10 \%$, otherwise an unfavorable crystal phase is formed. Compared with pristine, the $\mathrm{Na}_{0.67} \mathrm{CoO}_{2}, \mathrm{Na}_{0.67} \mathrm{Co}_{0.90} \mathrm{Ti}_{0.10} \mathrm{O}_{2}$ possesses an improved cycling life and larger energy density. It should be noted that if the content of $\mathrm{Ti}$ increases more than $10 \%$, the rate capability will decrease.

Over recent years, $\mathrm{P} 2-\mathrm{Na}_{\mathrm{x}} \mathrm{CoO}_{2}$ has been regarded as an available cathode material for solid state SIBs. For example, a novel solid state sodium polymer battery consisting of a $\mathrm{Na}_{0.7} \mathrm{CoO}_{2}$ cathode, PEO-based electrolyte and Na metal anode has been reported by Singh et al.[148] Under the optimized conditions, this battery exhibits a specific capacity of $\sim 138 \mathrm{mAh} \mathrm{g}^{-1}$ at $0.1 \mathrm{C}$ with a Coulombic efficiency of $99 \%$. To further enhance the electrochemical performance, $\mathrm{Na}_{0.7} \mathrm{CoO}_{2}$ material that can be combined with some sodium oxyacids. ${ }^{133}$ Briefly, $\mathrm{Na}_{0.7} \mathrm{CoO}_{2}$ when ball-milled with several sodium oxyacids (including $\mathrm{NaNO}_{3}, \mathrm{Na}_{2} \mathrm{SO}_{4}, \mathrm{Na}_{3} \mathrm{PO}_{4}, \mathrm{NaBO}_{3}$ or $\mathrm{Na}_{2} \mathrm{CO}_{3}$ ), can form an amorphous cathode material. It should be pointed that when tested in a cell with a $\mathrm{Na}_{3} \mathrm{PS}_{4}$ solid electrolyte, the sodium oxyacids can enhance the malleability and ionic conductivity of $\mathrm{Na}_{0.7} \mathrm{CoO}_{2}$. In particular, $\mathrm{Na}_{0.7} \mathrm{CoO}_{2}-\mathrm{NaNO}_{3}$ hybrid cathodes shows the highest ionic conductivity and capacity of $170 \mathrm{mAh} \mathrm{g}^{-1}$ in the 5th cycle. However, the rate capability of solid sodium battery assembled by $\mathrm{P} 2-\mathrm{Na}_{0.7} \mathrm{CoO}_{2}$ cathode should be further improved.

\section{Conclusion and Outlook}

As a promising candidate for grid-scale energy storage, SIBs have attract great attention due to the low-cost of sodium resources and electrochemical characteristics similar to those of LIBs. From the commercialization perspective, the primary parameters are the production and operation costs and long-term cycling capability. During the past few years, some achievements have already built upon the electrode material for SIB with high energy density and long cycle stability comparable to LIB counterparts. In addition, some new understanding of the $\mathrm{Na}^{+}$ion intercalation chemistry offers new design ideas for novel electrode materials that are potentially low-cost and scalable for manufacture. As a result, some classic materials with a long research history have been revitalized, including cobalt-based materials. Cobalt-based materials, as cathode or anode materials, are promising candidates for achieving high-performance SIBs for large-scale energy storage applications. The structure and specific capacities (practical and theoretical values) of 
representative cobalt-based materials reported in recent years for SIBs are a foundation of SIB development based on LIBs and the knowledge from conversion mode systems and Li-S systems.

The layered $\mathrm{P} 2-\mathrm{Na}_{\mathrm{x}} \mathrm{CoO}_{2}$, which has a longer history than $\mathrm{LiCoO}_{2}$, faces the challenge of sufficient cycling stability because of the unavoidable intrinsic complex structural redistribution during $\mathrm{Na}^{+}$insertion/extraction. Using a strategy of suitable element doping/substitution, the fast degradation in the capacity may be mitigated or supressed. This is a promising way to overcome the inherent defects of $\mathrm{P} 2-\mathrm{Na}_{\mathrm{x}} \mathrm{CoO}_{2}$. Combined with rational structure design, the future of this layered metal oxide and its isostructural counterparts are expected to be useful in SIB electrode development.

For anode materials, various cobalt oxides, sulfides and selenides are all hindered by the conversion reactions, which creates shortcomings such as low reversibility, sluggish kinetics and large volume change especially when deep discharged to lower voltages. Although conversion reactions can deliver high theoretical capacities, most of the electrodes exhibit reversible capacities (in a limited voltage window) far lower than the theoretical values, indicating that oxide-based anodes require alternative material developments to offset low voltage influence on energy density for SIBs, as is te case for LIBs. One approach that tackles $\mathrm{NA}^{+}$insertion and volumetric expanstion is carbon coating and electrical wiring. Another is the development of binder and conductive additive-free formaulations that offset energy density loss to some degree, in cases where the lower voltage range is limited to avoid conversion reactions. This approach saves weight in the electrode formation. Cobalt chalcogenides have the higher conductivities than their metal oxide counterparts do. Thus, they are more promising than cobalt oxides for SIBs. It should be noted that the final products of the conversion reaction, $\mathrm{Na}_{2} \mathrm{~S}$ and $\mathrm{Na}_{2} \mathrm{Se}$, are similar to the Na-S battery and Na-Se battery. Maybe a successful strategy in these two fields are also effective to enhance the electrochemical performance of cobalt chalcogenides. In addition, the relationship between an ether-based electrolyte and the electrochemical behaviors of the cobalt-based anode should be studied more systematically in future.

By increasing the detail of the electrode design, such as with carbon decoration and nanostructuring, the cycle stability and rate capability can still be improved. Although many significant challenges lie ahead, the rapid advances in recent years by many researchers, together with the sustained interest from industrial and academic communities, indicate that cobalt-based 
electrode materials are worth further investigation in the pursuit of low-cost, long-term life of SIBs.

\section{Acknowledgements}

This work was supported by the National Natural Science Foundation of China (Grant

No. 51302079), and the Natural Science Foundation of Hunan Province (Grant No.

2017JJ1008).

\section{References}

1. Fang, Y., et al., Energy Storage: Recent Progress in Iron-Based Electrode Materials for Grid-Scale Sodium-Ion Batteries. Small, 2018. 14(9): 1703116.

2. Pan, H.L., Y.S. Hu, and L.Q. Chen, Room-Temperature Stationary Sodium-Ion Batteries for Large-Scale Electric Energy Storage. Energy \& Environmental Science, 2013. 6(8): 2338.

3. Sun, Y., N. Liu, and Y. Cui, Promises and challenges of nanomaterials for lithium-based rechargeable batteries. Nature Energy, 2016. 1(7): 16071.

4. Aravindan, V., Y.S. Lee, and S. Madhavi, Research Progress on Negative Electrodes for Practical Li-Ion Batteries: Beyond Carbonaceous Anodes. Advanced Energy Materials, 2015: 1402225.

5. Bruce, D., K. Haresh, and T. Jean-Marie, Electrical energy storage for the grid: a battery of choices. Science, 2011.334 (6058): 928.

6. Slater, M.D., et al., Sodium-Ion Batteries. Advanced Functional Materials, 2013. 23(8): 947.

7. Ortiz-Vitoriano, N., et al., High performance manganese-based layered oxide cathodes: overcoming the challenges of sodium ion batteries. Energy \& Environmental Science, 2017. 10: 1051 .

8. Palomares, V., et al., Na-ion Batteries, Recent Advances and Present Challenges to Become low Cost Energy Storage Systems. Energy \& Environmental Science, 2012. 5(3): 5884-5901.

9. Fang C, Huang Y, Zhang W, et al. Routes to High Energy Cathodes of Sodium-Ion Batteries. Advanced Energy Materials, 2016, 6(5): 1501727.

10. Han M H, Gonzalo E, Singh G, et al. A comprehensive review of sodium layered oxides: powerful cathodes for Na-ion batteries[J]. Energy \& Environmental Science, 2015, 8(1): 81.

11. Hou, H., et al., Carbon Anode Materials for Advanced Sodium-Ion Batteries. Advanced Energy Materials, 2017. 7(24): 1602898.

12. Wen, Y., et al., Expanded graphite as superior anode for sodium-ion batteries. Nature Communications, 2014. 5: 4033.

13. Chen W, Qi S, Guan L, et al. Pyrite $\mathrm{FeS}_{2}$ microspheres anchoring on reduced graphene oxide aerogel as an enhanced electrode material for sodium-ion batteries. Journal of Materials Chemistry A, 2017, 5(11): 5332. 
14. Zhao Y, Wang L P, Sougrati M T, et al. A review on design strategies for carbon based metal oxides and sulfides nanocomposites for high performance Li and $\mathrm{Na}$ ion battery anodes[J]. Advanced Energy Materials, 2017, 7(9): 1601424.

15. Cui, J., S. Yao, and J.K. Kim, Recent progress in rational design of anode materials for high-performance Na-ion batteries. Energy Storage Materials, 2017. 7: 64

16. Amrtha, B., et al., Electrochemical stability of non-aqueous electrolytes for sodium-ion batteries and their compatibility with $\mathrm{Na}_{0.7} \mathrm{CoO}_{2}$. Physical Chemistry Chemical Physics, 2014. 16(5): 1987.

17. Hwang, S., et al., Investigation of Thermal Stability of $\mathrm{P} 2-\mathrm{Na}_{\mathrm{x}} \mathrm{CoO}_{2}$ Cathode Materials for Sodium Ion Batteries using Real-Time Electron Microscopy. Acs Applied Materials \& Interfaces, 2017. 9(22): 18883.

18. Vassilaras $\mathrm{P}, \mathrm{Ma} \mathrm{X}, \mathrm{Li}$ X, et al. Electrochemical properties of monoclinic $\mathrm{NaNiO}_{2}$. Journal of The Electrochemical Society, 2013, 160(2): A207.

19. Zhao, J., et al., Electrochemical and Thermal Properties of $\alpha-\mathrm{NaFeO}_{2}$ Cathode for Na-Ion Batteries. Journal of Power Sources, 2013. 244(5): 752.

20. Ding, J.J., et al., Cycle performance improvement of $\mathrm{NaCrO}_{2}$ cathode by carbon coating for sodium ion batteries. Electrochemistry Communications, 2012. 22(1): 85.

21. Zhu, Y., et al., Comparison of electrochemical performances of olivine $\mathrm{NaFePO}_{4}$ in sodium-ion batteries and olivine $\mathrm{LiFePO}_{4}$ in lithium-ion batteries. Nanoscale, 2012. 5(2): 780.

22. Rui, X., et al., An Advanced Sodium-Ion Battery Composed of Carbon Coated $\mathrm{Na}_{3} \mathrm{~V}_{2}\left(\mathrm{PO}_{4}\right)_{3}$ in a Porous Graphene Network. Advanced Materials, 2016. 27(42): 6670.

23. Wang, Q., et al., Research Progress on Vanadium-based Cathode Materials for Sodium Ion Batteries. Journal of Materials Chemistry A, 2018, 6, 8815.

24. Shakoor, R.A., et al., A combined first principles and experimental study on $\mathrm{Na}_{3} \mathrm{~V}_{2}\left(\mathrm{PO}_{4}\right)_{2} \mathrm{~F}_{3}$ for rechargeable Na batteries. Journal of Materials Chemistry, 2012. 22(38): 20535.

25. Sauvage, F., et al., Crystal Structure and Electrochemical Properties vs. $\mathrm{Na}^{+}$of the Sodium Fluorophosphate $\mathrm{Na}_{1.5} \mathrm{VOPO}_{4} \mathrm{~F}_{0.5}$. Cheminform, 2007. 8(10): 1215.

26. Tripathi, R., et al., Na-ion mobility in layered $\mathrm{Na}_{2} \mathrm{FePO}_{4} \mathrm{~F}$ and olivine $\mathrm{Na}[\mathrm{Fe}, \mathrm{Mn}] \mathrm{PO}_{4}$. Energy \& Environmental Science, 2013. 6(8): 2257.

27. Li, C., et al., Top-Down Synthesis of Open Framework Fluoride for Lithium and Sodium Batteries. Chemistry of Materials, 2013. 25(6): 962.

28. Guntlin, C., et al., Nanocrystalline $\mathrm{FeF}_{3}$ and $\mathrm{MF}_{2}(\mathrm{M}=\mathrm{Fe}, \mathrm{Co}, \mathrm{Mn})$ from Metal Trifluoroacetates and their $\mathrm{Li}(\mathrm{Na})$-ion Storage Properties. Journal of Materials Chemistry A, 2017. 5(16): 7383.

29. Zhao, Q., Y. Lu, and J. Chen, Advanced Organic Electrode Materials for Rechargeable Sodium-Ion Batteries. Advanced Energy Materials, 2017. 7: 1601792.

30. Li, X., et al., Materials Based on Antimony and Bismuth for Sodium Storage. Chem. Eur. J., 2018. 24: 13719 .

31. Wang, L.P., Recent developments in electrode materials for sodium-ion batteries. Journal of Materials Chemistry A, 2015. 3(18): 9353.

32. Z, H., et al., Advances and Challenges in Metal Sulfides/Selenides for Next-Generation Rechargeable Sodium-Ion Batteries. Advanced Materials, 2017. 29(48).

33. Xiao Y, Lee S H, Sun Y K. The application of metal sulfides in sodium ion batteries[J]. Advanced Energy Materials, 2017, 7(3): 1601329. 
34. Yongye, L., et al., $\mathrm{Co}_{3} \mathrm{O}_{4}$ nanocrystals on graphene as a synergistic catalyst for oxygen reduction reaction. Nature Materials, 2011. 10(10): 780.

35. Koshibae, W., K. Tsutsui, and S. Maekawa, Thermopower in cobalt oxides. Phys.rev.b, 2000. 62(11): 6869 .

36. $\mathrm{Hu}$, X.W., et al., Starfish-shaped $\mathrm{Co}_{3} \mathrm{O}_{4} / \mathrm{ZnFe}_{2} \mathrm{O}_{4}$ Hollow Nanocomposite: Synthesis, Supercapacity, and Magnetic Properties. Acs Applied Materials \& Interfaces, 2015. 7(18): p. 9972.

37. Lou X W, Deng D, Lee J Y, et al. Self - supported formation of needlelike $\mathrm{Co}_{3} \mathrm{O}_{4}$ nanotubes and their application as lithium - ion battery electrodes. Advanced Materials, 2008. 20(2): 258.

38. Lou, X.W., et al., Self-Supported Formation of Needlelike $\mathrm{Co}_{3} \mathrm{O}_{4}$ Nanotubes and Their Application as Lithium-Ion Battery Electrodes. Advanced Materials, 2010. 20(2): 258.

39. Park, S.K., K.K. Jin, and C.K. Yun, Metal-organic framework-derived $\mathrm{CoSe}_{2} /(\mathrm{NiCo}) \mathrm{Se}_{2}$ box-in-box hollow nanocubes with enhanced electrochemical properties for sodium-ion storage and hydrogen evolution. Journal of Materials Chemistry A, 2017. 5(35).

40. Salunkhe, R.R., et al., Asymmetric Supercapacitors Using 3D Nanoporous Carbon and Cobalt Oxide Electrodes Synthesized from a Single Metal-Organic Framework. Acs Nano, 2015. 9(6): 6288.

41. Du, N., et al., Porous $\mathrm{Co}_{3} \mathrm{O}_{4}$ Nanotubes Derived From $\mathrm{Co}_{4}(\mathrm{CO})_{12}$ Clusters on Carbon Nanotube Templates: A Highly Efficient Material For Li-Battery Applications. Advanced Materials, 2010. 19(24): 4505.

42. Matsumoto, $\mathrm{H}$., et al., Fast cycling of $\mathrm{Li} / \mathrm{LiCoO}_{2}$ cell with low-viscosity ionic liquids based on bis(fluorosulfonyl)imide [FSI] $]^{-}$. Journal of Power Sources, 2006. 160(2): 1308.

43. Xia X, Dahn J R. A study of the reactivity of de-intercalated $\mathrm{P} 2-\mathrm{Na}_{\mathrm{x}} \mathrm{CoO}_{2}$ with non-aqueous solvent and electrolyte by accelerating rate calorimetry. Journal of the Electrochemical Society, 2012, 159(5): A647.

44. Wen, J.W., et al., $\mathrm{Li}$ and $\mathrm{Na}$ storage behavior of bowl-like hollow $\mathrm{Co}_{3} \mathrm{O}_{4}$ microspheres as an anode material for lithium-ion and sodium-ion batteries. Electrochimica Acta, 2014. 132(19): 193.

45. Kang, W., et al., Metal-Organic Framework Derived Porous Hollow $\mathrm{Co}_{3} \mathrm{O}_{4} / \mathrm{N}-\mathrm{C}$ Polyhedron Composite with Excellent Energy Storage Capability. ACS Appl Mater Interfaces, 2017. 9(12): 10602.

46. Park, G.D. and Y.C. Kang, One-Pot Synthesis of CoSe $e_{\mathrm{x}}-\mathrm{rGO}$ Composite Powders by Spray Pyrolysis and Their Application as Anode Material for Sodium-Ion Batteries. Chemistry, 2016. 22(12): 4140

47. Park, S.K., K.K. Jin, and C.K. Yun, Metal-organic framework-derived $\mathrm{CoSe}_{2} /(\mathrm{NiCo}) \mathrm{Se}_{2}$ box-in-box hollow nanocubes with enhanced electrochemical properties for sodium-ion storage and hydrogen evolution. Journal of Materials Chemistry A, 2017. 5(35): 18823.

48. Han, F., et al., Dual-carbon phase-protective cobalt sulfide nanoparticles with cable-type and mesoporous nanostructure for enhanced cycling stability in sodium and lithium ion batteries. Carbon, 2017, 118: 731.

49. Wilson, J.R., et al., Measurement of three-dimensional microstructure in a $\mathrm{LiCoO}_{2}$ positive electrode. Journal of Power Sources, 2016. 196(7): 3443. 
50. Shibata, T., et al., Fast discharge process of layered cobalt oxides due to high $\mathrm{Na}^{+}$diffusion. Sci. Rep., 2015. 5: 9006.

51. Yu H, Brown Z L, Wei C, et al. Thermoelectrochemical Activation of $\mathrm{CoO}$ in Na Cells. Journal of The Electrochemical Society, 2018, 165(9): A1595.

52. Mao Z, Zhou M, Wang K, et al. Electrospinning synthesis of $\mathrm{Co}_{3} \mathrm{O}_{4} @ \mathrm{C}$ nanofibers as a high-performance anode for sodium ion batteries. RSC Advances, 2017, 7(37): 23122.

53. Fu B, Zhou X, Wang Y. $\mathrm{Co}_{3} \mathrm{O}_{4}$ carbon nanofiber mats as negative electrodes for sodium-ion batteries. Materials Letters, 2016, 170: 21.

54. Zhang Y, Wang N, Xue P, et al. $\mathrm{Co}_{9} \mathrm{~S}_{8} @$ carbon nanospheres as high-performance anodes for sodium ion battery. Chemical Engineering Journal, 2018, 343: 512.

55. Zhao, Y., et al., Self-assembled CoS nanoflowers wrapped in reduced graphene oxides as the high-performance anode materials for sodium-ion batteries. Chemistry, 2017. 23(53).

56. Jia H, Dirican M, Chen C, et al. Carbon-coated CoS@rGO anode material with enhanced cyclic stability for sodium storage. Materials Letters, 2018, 233: 158.

57. Cui, C., et al., Quasi-reversible conversion reaction of $\mathrm{CoSe}_{2} /$ nitrogen-doped carbon nanofibers towards long-lifetime anode materials for sodium-ion batteries. Journal of Materials Chemistry A, 2018, 6, 7088.

58. Zhang, N., et al., 3D Porous $\gamma-\mathrm{Fe}_{2} \mathrm{O}_{3} @ \mathrm{C}$ Nanocomposite as High-Performance Anode Material of Na-Ion Batteries. Advanced Energy Materials, 2014, 1401123.

59. Chen, D., et al., Two-Dimensional Holey $\mathrm{Co}_{3} \mathrm{O}_{4}$ Nanosheets for High-Rate Alkali-Ion Batteries: From Rational Synthesis to in Situ Probing. Nano Letters, 2017. 17(6): 3907.

60. Sreedhara, M. B., Santhosha, A. L., Bhattacharyya A. J., and . Rao, C. N. R., Composite of few-layer $\mathrm{MoO}_{3}$ nanosheets with graphene as a high performance anode for sodiumion batteries. J. Mater. Chem. A, 2016, 4, 9466.

61. Zhou, M., et al., Amorphous $\mathrm{TiO}_{2}$ inverse opal anode for high-rate sodium ion batteries. Nano Energy, 2017. 31: 514.

62. Xin, D., et al., Mesocrystal hexagonal $\mathrm{Co}_{3} \mathrm{O}_{4}$ nanosheets for high performance lithium and sodium-ion batteries. Materials Letters, 2017. 209: 388.

63. Dou, Y., et al., Atomically thin $\mathrm{Co}_{3} \mathrm{O}_{4}$ nanosheet-coated stainless steel mesh with enhanced capacitive $\mathrm{Na}+$ storage for high-performance sodium-ion batteries. 2d Materials, 2016. 4(1): 015022 .

64. Klavetter, K.C., et al., Li- and Na-reduction products of meso- $\mathrm{Co}_{3} \mathrm{O}_{4}$ form high-rate, stably cycling battery anode materials. Journal of Materials Chemistry A, 2014. 2(34): 14209.

65. Jian, Z., et al., Monodispersed hierarchical $\mathrm{Co}_{3} \mathrm{O}_{4}$ spheres intertwined with carbon nanotubes for use as anode materials in sodium-ion batteries. Journal of Materials Chemistry A, 2014. 2(34): 13805 .

66. Deng, Q., L. Wang, and J. Li, Electrochemical characterization of $\mathrm{Co}_{3} \mathrm{O}_{4} / \mathrm{MCNTs}$ composite anode materials for sodium-ion batteries. Journal of Materials Science, 2015. 50(11): 4142.

67. Wang Z, Zhang S, Yue L, et al. Synthesis of $\mathrm{Co}_{3} \mathrm{O}_{4}$ nanocubes/CNTs composite with enhanced sodium storage performance. Solid State Ionics, 2017, 312: 32.

68. Lu, Y. and E. Fong, Botanic chemistry enabled synthesis of 3D hollow metal oxides/carbon hybrids for ultra-high performance metal-ion batteries. 2017, 4: 89. 
69. Wang, Y., et al., Superior sodium-ion storage performance of $\mathrm{Co}_{3} \mathrm{O}_{4} @$ Nitrogen-doped carbon: Derived from a metal-organic framework. Journal of Materials Chemistry A, 2016. 4(15): 5428.

70. Kim, H., et al., Understanding Origin of Voltage Hysteresis in Conversion Reaction for $\mathrm{Na}$ Rechargeable Batteries: The Case of Cobalt Oxides. Advanced Functional Materials, 2016. 26(28): 5042 .

71. Longoni $\mathrm{G}$, Fiore $\mathrm{M}, \mathrm{Kim} \mathrm{J} \mathrm{H}$, et al. $\mathrm{Co}_{3} \mathrm{O}_{4}$ negative electrode material for rechargeable sodium ion batteries: An investigation of conversion reaction mechanism and morphology-performances correlations. Journal of Power Sources, 2016, 332: 42.

72. $\mathrm{Li} \mathrm{H} \mathrm{H,} \mathrm{Li} \mathrm{Z} \mathrm{Y,} \mathrm{Wu} \mathrm{X} \mathrm{L,} \mathrm{et} \mathrm{al.} \mathrm{Shale-like} \mathrm{Co}_{3} \mathrm{O}_{4}$ for high performance lithium/sodium ion batteries. Journal of Materials Chemistry A, 2016, 4(21): 8242.

73. $\mathrm{Li} \mathrm{Q}, \mathrm{Wu} \mathrm{J}, \mathrm{Xu} \mathrm{J}$, et al. Synergistic sodiation of cobalt oxide nanoparticles and conductive carbon nanotubes (CNTs) for sodium-ion batteries. Journal of Materials Chemistry A, 2016, 4(22): 8669.

74. Md Mokhlesur, R., et al., Electrochemical investigation of sodium reactivity with nanostructured $\mathrm{Co}_{3} \mathrm{O}_{4}$ for sodium-ion batteries. Chemical Communications, 2014. 45(28): 5057.

75. Rahman, M.M., et al., Ex situ electrochemical sodiation/desodiation observation of $\mathrm{Co}_{3} \mathrm{O}_{4}$ anchored carbon nanotubes: a high performance sodium-ion battery anode produced by pulsed plasma in a liquid. Nanoscale, 2015. 7(30): 13088.

76. Liu, Y., et al., Mesoporous $\mathrm{Co}_{3} \mathrm{O}_{4}$ sheets/3D graphene networks nanohybrids for high-performance sodium-ion battery anode. Journal of Power Sources, 2015. 273: 878.

77. $\mathrm{Wu}, \mathrm{Y}$, et al., Interface-modulated fabrication of hierarchical yolk-shell $\mathrm{Co}_{3} \mathrm{O}_{4} / \mathrm{C}$ dodecahedrons as stable anodes for lithium and sodium storage. Nano Research, 2017. 10(7): 1 .

78. $\mathrm{Xu} \mathrm{H}$, Zhu G, Hao B. Metal-organic frameworks derived flower-like $\mathrm{Co}_{3} \mathrm{O}_{4} /$ nitrogen doped graphite carbon hybrid for high-performance sodium-ion batteries. Journal of Materials Science \& Technology, 2019, 35(1): 100.

79. Ko, Y.N., S.H. Choi, and Y.C. Kang, Hollow Cobalt Selenide Microspheres: Synthesis and Application as Anode Materials for Na-Ion Batteries. Acs Applied Materials \& Interfaces, 2016. 8(10): 6449.

80. Li, X., et al., Highly reversible and fast sodium storage boosted by improved interfacial and surface charge transfer derived from the synergistic effect of heterostructures and pseudocapacitance in $\mathrm{SnO}_{2}$-based anodes. Nanoscale, 2018. 10(5): 2301.

81. Fang G, Zhou J, Cai Y, et al. Metal - organic framework-templated two-dimensional hybrid bimetallic metal oxides with enhanced lithium/sodium storage capability. Journal of Materials Chemistry A, 2017, 5(27): 13983.

82. Zhang, Wenming, et al. "Carbon - Encapsulated Tube-Wire Co3O4/MnO2 Heterostructure Nanofibers as Anode Material for Sodium - Ion Batteries." Particle \& Particle Systems Characterization. 2018, 35: 1800138.

83. Han, Y., et al., Zinc/Nickel-Doped Hollow Core-Shell $\mathrm{Co}_{3} \mathrm{O}_{4}$ Derived from a Metal-Organic Framework with High Capacity, Stability, and Rate Performance in Lithium/Sodium-Ion Batteries. Chemistry-A European Journal, 2017. 24(7): 1651. 
84. Chang L, Wang K, Huang L, et al. Hierarchically porous CoO microsphere films with enhanced lithium/sodium storage properties. Journal of Alloys and Compounds, 2017, 725 : 824.

85. Chang, L., et al., Hierarchical $\mathrm{CoO}$ microflower film with excellent electrochemical lithium/sodium storage performance. Journal of Materials Chemistry A, 2017. 5: 20892.

86. Kaneti, Y.V., et al., Fabrication of an MOF-derived heteroatom-doped $\mathrm{Co} / \mathrm{CoO} /$ carbon hybrid with superior sodium storage performance for sodium-ion batteries. Journal of Materials Chemistry A, 2017. 5: 15356.

87. Xia, H., et al., $\operatorname{CoS}_{2}$ nanodots trapped within graphitic structured N-doped carbon spheres with efficient performances for lithium storage. Journal of Materials Chemistry A, 2018, 6, 7148.

88. Liu, X., et al., Synthesis of the Carbon-Coated Nanoparticle $\mathrm{Co}_{9} \mathrm{~S}_{8}$ and Its Electrochemical Performance as an Anode Material for Sodium-Ion Batteries. Langmuir, 2016. 32(48): 12593.

89. Hu, Xiang, et al. Reliable and General Route to Inverse Opal Structured Nanohybrids of Carbon-Confined Transition Metal Sulfides Quantum Dots for High-Performance Sodium Storage. Advanced Energy Materials 2018, 8: 1801452.

90. Zhao, Y., et al., $\mathrm{Co}_{9} \mathrm{~S}_{8} / \mathrm{Co}$ as a High Performance Anode for Sodium Ion Batteries with a Preferred Ether-based Electrolyte. Chemsuschem, 2017. 10: 4778.

91. Wang, H., et al., $\mathrm{Co}_{1-\mathrm{x}} \mathrm{S}$-graphene hybrid: a high-performance metal chalcogenide electrocatalyst for oxygen reduction. Angew Chem Int Ed Engl, 2011. 50(46): 10969.

92. Chen, Z., et al., General Synthesis of Dual Carbon-Confined Metal Sulfides Quantum Dots Toward High-Performance Anodes for Sodium-Ion Batteries. Advanced Functional Materials, 2017. 27, 1702046.

93. Cui, C., et al., Three-dimensional carbon frameworks enabling $\mathrm{MoS}_{2}$ as anode for dual ion batteries with superior sodium storage properties. Energy Storage Materials, 2018. 15: 22.

94. Wang, Y., et al., A yolk-shelled $\mathrm{Co}_{9} \mathrm{~S}_{8} / \mathrm{MoS}_{2}-\mathrm{CN}$ nanocomposite derived from a metal-organic framework as a high performance anode for sodium ion batteries. Journal of Materials Chemistry A, 2018. 6(11): 4776.

95. Liu, X., et al., Facile synthesis and electrochemical sodium storage of $\mathrm{CoS}_{2}$ micro/nano-structures. Nano Research, 2016. 9(1): 198.

96. Li, Zhiwei, et al. $\backslash$ Flaky $\operatorname{CoS} 2$ and graphene nanocomposite anode materials for sodium-ion batteries with improved performance. RSC Advances, 2016, 6: 70632.

97. Han, F., et al., In situ formation of ultrafine $\mathrm{CoS}_{2}$ nanoparticles uniformly encapsulated in N/S-doped carbon polyhedron for advanced sodium-ion batteries. Rsc Advances, 2017. 7(49): 30699.

98. Yuelei Pan, Xudong Cheng, Lunlun Gong, Long Shi, Yurui Denga and Heping Zhang. Highly reversible $\mathrm{Na}$ ion storage in $\mathrm{N}$-doped polyhedral carbon-coated transition-metal chalcogenides by optimizing the nanostructure and surface engineering. J. Mater. Chem. A, 2018, 6, 18967.

99. Pan, Y., et al., $\mathrm{CoS}_{2}$ Nanoparticles Wrapping on Flexible Freestanding Multichannel Carbon Nanofibers with High Performance for Na-Ion Batteries. Acs Appl Mater Interfaces, 2017. 9(41): 35820 .

100. Zulipiya, S., et al., Improved electrochemical performance of $\mathrm{CoS}_{2}$-MWCNT nanocomposites for sodium-ion batteries. Chemical Communications, 2015. 51(52): 10486. 
101. Xie, Kongyan, et al. A strongly coupled $\mathrm{CoS}_{2} /$ reduced graphene oxide nanostructure as an anode material for efficient sodium-ion batteries. Journal of Alloys and Compounds, 2017, 726: 394.

102. Xing, Z., et al., Cobalt disulfide nanoparticles/graphene/carbon nanotubes aerogels with superior performance for lithium and sodium storage. Journal of Colloid \& Interface Science, 2017, 505: 23 .

103. Pan, Y., et al., Nanoflower-like N-doped $\mathrm{C} / \mathrm{CoS}_{2}$ as high-performance anode materials for Na-ion batteries. Nanoscale, 2018. 10(44): 20813.

104. Pan, Y., et al., Double-Morphology $\mathrm{CoS}_{2}$ Anchored on N-Doped Multichannel Carbon Nanofibers as High-Performance Anode Materials for Na-Ion Batteries. ACS Appl Mater Interfaces, 2018, 10(37): 31441.

105. Shi, L., et al., $\mathrm{SnS}_{2}$ Nanosheets Coating on Nanohollow Cubic $\mathrm{CoS}_{2} / \mathrm{C}$ for Ultralong Life and High Rate Capability Half/Full Sodium-Ion Batteries. Small, 2018. 14(41): 1802716.

106. Wang, X., et al., Improved Electrochemical Performance Based on Nanostructured $\mathrm{SnS}_{2} @ \mathrm{CoS}_{2}$-rGO Composite Anode for Sodium-Ion Batteries. Nano-Micro Letters, 2018. 10(3): 46.

107. Lin, Y., et al., $\mathrm{NiS}_{2} @ \mathrm{CoS}_{2}$ nanocrystals encapsulated in N-doped carbon nanocubes for high performance lithium/sodium ion batteries. Energy Storage Materials, 2018, 11, 67.

108. Ma, Y., et al., Cobalt Disulfide Nanoparticles Embedded in Porous Carbonaceous Micro-Polyhedrons Interlinked by Carbon Nanotubes for Superior Lithium and Sodium Storage. Acs Nano, 2018. 12: 7220.

109. Wu, R., et al., In-situ formation of hollow hybrids composed of cobalt sulfides embedded within porous carbon polyhedra/carbon nanotubes for high-performance lithium-ion batteries. Advanced Materials, 2015. 27(19): 3038.

110. Zhou, Limin, et al. Structural and chemical synergistic effect of CoS nanoparticles and porous carbon nanorods for high-performance sodium storage. Nano Energy. 2017, 35: 281.

111. Zhou, Q., et al., Sandwich-like cobalt sulfide-graphene composite-an anode material with excellent electrochemical performance for sodium ion batteries. Rsc Advances, 2015. 5(88): 71644.

112. Wu, C., et al., Peapod-Like Carbon-Encapsulated Cobalt Chalcogenide Nanowires as Cycle-Stable and High-Rate Materials for Sodium-Ion Anodes. Advanced Materials, 2016. 28(33): 7276

113. Zhu, Xiaoming, et al. Amorphous CoS nanoparticle/reduced graphene oxide composite as high-performance anode material for sodium-ion batteries. Ceramics International. 2017, 13: 9630.

114. Peng, S., et al., Unique Cobalt Sulfide/Reduced Graphene Oxide Composite as an Anode for Sodium-Ion Batteries with Superior Rate Capability and Long Cycling Stability. Small, 2016. 12(10): 1359 .

115. Han, F., C.Y.J. Tan, and Z. Gao, Template-free formation of carbon nanotube-supported cobalt sulfide@carbon hollow nanoparticles for stable and fast sodium ion storage. Journal of Power Sources, 2017. 339: 41.

116. Zhang, Y., et al., Boosting Sodium-Ion Storage by Encapsulating NiS(CoS) Hollow Nanoparticles into Carbonaceous Fibers. ACS Appl Mater Interfaces, 2018. 10(47): 40531 
117. Yu, J., et al., CoS@sulfur doped onion-like carbon nanocapsules with excellent cycling stability and rate capability for sodium-ion batteries. Ceramics International, 2018, 44: 17133.

118. Guo, Q., et al., Cobalt Sulfide Quantum Dots Embedded N/S-Doped Carbon Nanosheets with Superior Reversibility and Rate Capability for Sodium-Ion Batteries. Acs Nano, 2017. 11(12): 12658 .

119. Liu X, Ma H, Liu Q, et al. Ethylenediamine-assisted synthesis of microsized cobalt sulfide as advanced anode materials for sodium ion batteries. Journal of Alloys and Compounds, 2018, 735: 765.

120. Li, Q., et al., Self-adaptive mesoporous CoS@alveolus-like carbon yolk-shell microsphere for alkali cations storage. Nano Energy, 2017. 41: 109.

121. Park, S.K., K.K. Jin, and C.K. Yun, Excellent Sodium-Ion Storage Performances of CoSe $\mathrm{S}_{2}$ Nanoparticles Embedded Within N-Doped Porous Graphitic Carbon Nanocube/Carbon Nanotube Composite. Chemical Engineering Journal, 2017. 328: 546.

122. Ma, X., L. Zou, and W. Zhao, Tailoring hollow microflower-shaped $\mathrm{CoSe}_{2}$ anodes in sodium ion batteries with high cycling stability. Chem Commun, 2018. 54(74): 10507.

123. Zhang, K., et al., Urchin-Like $\mathrm{CoSe}_{2}$ as a High-Performance Anode Material for Sodium-Ion Batteries. Advanced Functional Materials, 2016. 26(37): 6728.

124. Park, S.K. and Y.C. Kang, MOF-Templated N-Doped Carbon-Coated $\mathrm{CoSe}_{2}$ Nanorods Supported on Porous CNT Microspheres with Excellent Sodium-Ion Storage and Electrocatalytic Properties. ACS Appl Mater Interfaces, 2018. 10(20): 17203.

125. Ou X, Liang X, Zheng F, et al. In situ X-ray diffraction investigation of $\mathrm{CoSe}_{2}$ anode for Na-ion storage: Effect of cut-off voltage on cycling stability. Electrochimica Acta, 2017, 258: 1387-1396.

126. Wang, J., et al., Epitaxial Growth of Urchin-Like $\mathrm{CoSe}_{2}$ Nanorods from Electrospun Co-Embedded Porous Carbon Nanofibers and Their Superior Lithium Storage Properties. Particle \& Particle Systems Characterization, 2017. 34: 1700185.

127. Tang, Y., et al., Engineering Hollow Polyhedrons Structured from Carbon-Coated CoSe 2 Nanospheres Bridged by CNTs with Boosted Sodium Storage Performance. Journal of Materials Chemistry A, 2017. 5: 13591.

128. Cho, J.S., et al., Design and synthesis of multiroom-structured metal compounds-carbon hybrid microspheres as anode materials for rechargeable batteries. Nano Energy, 2016. 26: 466.

129. Kim J K, Kim J H, Kang Y C. Electrochemical properties of multicomponent oxide and selenide microspheres containing $\mathrm{Co}$ and Mo components with several tens of vacant nanorooms synthesized by spray pyrolysis. Chemical Engineering Journal, 2018, 333: 665.

130. Gao, J., et al., Rational Design of Hierarchical Nanotubes through Encapsulating $\mathrm{CoSe}_{2}$ Nanoparticles into $\mathrm{MoSe}_{2} / \mathrm{C}$ Composite Shells with Enhanced Lithium and Sodium Storage Performance. ACS Appl Mater Interfaces, 2018. 10(24): 20635.

131. Huang Y, Wang Z, Jiang Y, et al. Hierarchical porous $\mathrm{Co}_{0.85} \mathrm{Se} @$ reduced graphene oxide ultrathin nanosheets with vacancy-enhanced kinetics as superior anodes for sodium-ion batteries. Nano Energy, 2018, 53: 524.

132. Zhang $\mathrm{G}$, Liu $\mathrm{K}$, Liu $\mathrm{S}$, et al. Flexible $\mathrm{Co}_{0.85} \mathrm{Se}$ nanosheets/graphene composite film as binder-free anode with high Li-and Na-Ion storage performance. Journal of Alloys and Compounds, 2018, 731: 714 . 
133. Nagata Y, Nagao K, Deguchi M, et al. Amorphization of Sodium Cobalt Oxide Active Materials for High-Capacity All-Solid-State Sodium Batteries. Chemistry of Materials, 2018, 30(20): 6998

134. Li, Z., et al., First principles lattice dynamics of $\mathrm{NaCoO}_{2}$. Phys.rev.b, 2004, 70(14): 2806.

135. Medarde, M., et al., 1D to $2 \mathrm{D} \mathrm{Na}^{+}$ion diffusion inherently linked to structural transitions in $\mathrm{Na}_{0.7} \mathrm{CoO}_{2}$. Physical Review Letters, 2013. 110(26): 266401.

136. Braconnier, J.J., et al., Comportement electrochimique des phases $\mathrm{Na}_{\mathrm{x}} \mathrm{CoO}_{2}$. Materials Research Bulletin, 1980. 15(12): 1797.

137. Berthelot, R., D. Carlier, and C. Delmas. Electrochemical investigation of the $\mathrm{P} 2-\mathrm{Na}_{\mathrm{x}} \mathrm{CoO}_{2}$ phase diagram. Nature Materials, 2011. 10(1): 74

138. Delmas, C., et al., Electrochemical intercalation of sodium in $\mathrm{Na}_{\mathrm{x}} \mathrm{CoO}_{2}$ bronzes. Solid State Ionics, 1981, 3: 165.

139. Shacklette L W, Jow T R, Townsend L. Rechargeable electrodes from sodium cobalt bronzes. Journal of The Electrochemical Society, 1988, 135(11): 2669.

140. N, S., et al., Effect of titanium substitution in $\mathrm{P} 2-\mathrm{Na}_{2 / 3} \mathrm{Co}_{0.95} \mathrm{Ti}_{0.05} \mathrm{O}_{2}$ cathode material on the structural and electrochemical properties. Acs Appl Mater Interfaces, 2017, 9, 37778.

141. Fang, Y., X.Y. Yu, and X. Lou, A Practical High-Energy Cathode for Sodium-Ion Batteries Based on Uniform P2-Na ${ }_{0.7} \mathrm{CoO}_{2}$ Microspheres. Angewandte Chemie, 2017. 129(21): 5801

142. Gao, L., et al., Self-supported $\mathrm{Na}_{0.7} \mathrm{CoO}_{2}$ nanosheet arrays as cathodes for high performance sodium ion batteries. Journal of Power Sources, 2018. 396: 379.

143. Doubaji, S., et al., On the P2-NaxCo ${ }_{1-y}\left(\mathrm{Mn}_{2 / 3} \mathrm{Ni}_{1 / 3}\right)_{\mathrm{y}} \mathrm{O}_{2}$ Cathode Materials for Sodium-Ion Batteries: Synthesis, Electrochemical Performance, and Redox Processes Occurring during the Electrochemical Cycling. Acs Applied Materials \& Interfaces, 2018. 10(1): 488.

144. Su, C.H., et al., Ca-doped $\mathrm{Na}_{\mathrm{x}} \mathrm{CoO}_{2}$ for improved cyclability in sodium ion batteries. Journal of Power Sources, 2015. 277: 9.

145. Matsui, M., F. Mizukoshi, and N. Imanishi, Improved cycling performance of P2-type layered sodium cobalt oxide by calcium substitution. Journal of Power Sources, 2015. 280: 205.

146. Bianchini M, Wang J, Clément R, et al. A First-Principles and Experimental Investigation of Nickel Solubility into the $\mathrm{P} 2-\mathrm{Na}_{\mathrm{x}} \mathrm{CoO}_{2}$ Sodium-Ion Cathode. Advanced Energy Materials, 2018, 8(26): 1801446.

147. Kang, S.M., et al., $\mathrm{Na}^{+} /$vacancy disordered $\mathrm{P} 2-\mathrm{Na}_{0.67} \mathrm{Co}_{1-\mathrm{x}} \mathrm{Ti}_{\mathrm{x}} \mathrm{O}_{2}$ : high energy and high power cathode materials for sodium ion batteries. Acs Applied Materials \& Interfaces, 2018, 10(4): 3562.

148. Singh, V.K., et al., Electrochemical investigations of $\mathrm{Na}_{0.7} \mathrm{CoO}_{2}$ cathode with PEO-NaTFSI-BMIMTFSI electrolyte as promising material for Na-rechargeable battery. Journal of Solid State Electrochemistry, 2018, 8: 1. 


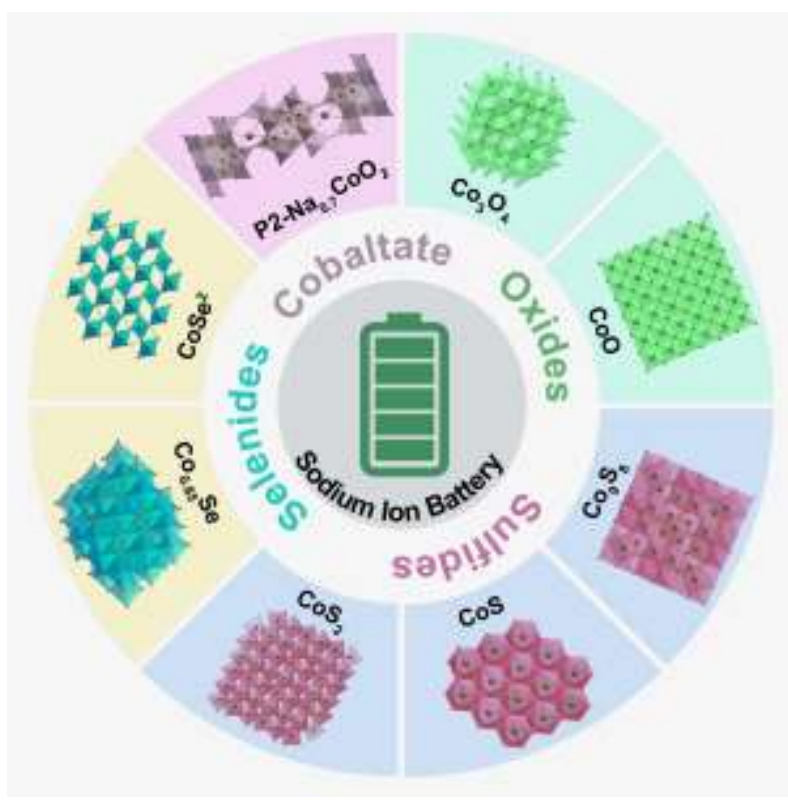

